\title{
Energy Paths in the European Union: A Model-Based Clustering Approach
}

\section{CCEP Working Paper 1701 Jan 2017}

Zsuzsanna Csereklyei*

Crawford School of Public Policy, The Australian National University

Paul W. Thurner

Political Science Department, Ludwig-Maximilians-University Munich (LMU)

\section{Johannes Langer}

Department of Statistics, Ludwig-Maximilians-University Munich (LMU)

\section{Helmut Küchenhoff}

Department of Statistics, Ludwig-Maximilians-University Munich (LMU)

\begin{abstract}
This paper examines typical "energy paths", i.e. the intertemporal development of the energy mixes of the member states of the European Union over 1971-2010. We apply model based clustering to detect major energy profiles and their compositional dynamics. The seven identified clusters show typical combinations of energy carriers dominating the primary energy consumption of a country. We find that countries tend to take a path towards higher quality energy mixes over time, however path inertia and dependencies arise from both infrastructure and resource endowments. Higher energy quality profiles are usually associated with higher national income and energy use per capita, supporting some evidence on the existence of a national-level energy ladder. We also find convergence in energy intensity over time, and a relationship between own resources and import dependency.
\end{abstract}




\section{Keywords:}

European Union, energy paths, path dependencies, model based clustering

\section{JEL Classification:}

Q40, Q48, O33, C11, C38

\section{Suggested Citation:}

Csereklyei, Z; Thurner, P.; Langer, J and Küchenhoff , H. (2017), Energy Paths in the European Union: A Model-Based Clustering Approach, CCEP Working Paper 1701, Jan 2017. Crawford School of Public Policy, The Australian National University.

\section{*Address for Correspondence:}

Zsuzsanna Csereklyei

Crawford School of Public Policy

The Australian National University

132 Lennox Crossing,

Acton, ACT 2601

Australia.

E-mail: zsuzsanna.csereklyei@anu.edu.au.

Phone: +61-2-6125-2295.

The Crawford School of Public Policy is the Australian National University's public policy school, serving and influencing Australia, Asia and the Pacific through advanced policy research, graduate and executive education, and policy impact.

The Centre for Climate Economics \& Policy is an organized research unit at the Crawford School of Public Policy, The Australian National University. The working paper series is intended to facilitate academic and policy discussion, and the views expressed in working papers are those of the authors. Contact for the Centre: Dr Frank Jotzo, frank.jotzo@anu.edu.au 


\title{
Energy Paths in the European Union: A Model-Based Clustering Approach
}

\author{
Zsuzsanna Csereklyei*, Crawford School of Public Policy, The Australian National \\ University
}

Paul W. Thurner, Political Science Department, Ludwig-Maximilians-University Munich (LMU)

Johannes Langer, Department of Statistics, Ludwig-Maximilians-University Munich (LMU)

Helmut Küchenhoff, Department of Statistics, Ludwig-Maximilians-University Munich (LMU)

24 January 2017

\begin{abstract}
:
This paper examines typical "energy paths", i.e. the intertemporal development of the energy mixes of the member states of the European Union over 1971-2010. We apply model based clustering to detect major energy profiles and their compositional dynamics. The seven identified clusters show typical combinations of energy carriers dominating the primary energy consumption of a country. We find that countries tend to take a path towards higher quality energy mixes over time, however path inertia and dependencies arise from both infrastructure and resource endowments. Higher energy quality profiles are usually associated with higher national income and energy use per capita, supporting some evidence on the existence of a national-level energy ladder. We also find convergence in energy intensity over time, and a relationship between own resources and import dependency.
\end{abstract}

\section{JEL Classification: Q40, Q48, O33, C11, C38}

Keywords: European Union, energy paths, path dependencies, model based clustering.

*Corresponding author: Zsuzsanna Csereklyei, Crawford School of Public Policy, The Australian National University, 132 Lennox Crossing, Acton, ACT 2601, Australia.

E-mail: zsuzsanna.csereklyei@anu.edu.au. Phone: +61-2-6125-2295. 


\section{Introduction}

The intertemporal composition of national energy mixes tends to exhibit specific patterns and dynamics over time and along the income spectrum (Burke, 2010 \& 2013). While countries generally transition towards higher-quality energy carriers over time (Csereklyei et al. 2016), the pace of this process is varying due to path dependencies caused by infrastructure, labor and capital lock-in (Sovacool, 2016), by prevailing perceptions (Lee and Gloaguen, 2015), policy inertia (Pierson, 2000), and by the abundance of indigenous resources (Burke, 2013). Whether and to what degree countries rely on diversified energy carriers (IEA, 2014a), and specifically depend on external resources (Jewell, 2011) during this transition, greatly influence their consecutive national (energy) security strategy (Cherp and Jewell, 2014). We argue that model-based cluster-analysis could provide completely new insights into this process. Specifically, we propose to cluster country-year energy profiles of the European Union over 1971-2010 in order to identify typical compositions and their behavior. The detected country profiles are investigated with regard to the changes they exhibit internally, and are used to test existing theories about the presence of an economy-wide energy ladder, energy intensity convergence and endowment lock-in effects.

The energy profile of a country is generally captured by the notion of the energy mix. This may refer to various underlying concepts: the contribution of different energy carriers to electricity generation (called the electricity mix), to primary energy consumption, or to primary energy production. Primary energy production tends to be dominated by indigenous energy carriers, while consumption often includes imports of non-indigenous resources. ${ }^{1}$ To gain however a full picture of a country’s energy profile including its long-term energy security implications (IEA, 2014a), in this study we investigate the composition of the primary consumption ${ }^{2}$.

The composition of national energy mixes may remain stable or exhibit systematic changes over time. We will call this behavior an energy path. The term path already suggests the possible presence of path dependencies (for the social sciences see: Pierson (2000), for technological development see Araujo and Harrison (2010), Araujo (2014), and Sovacool, (2016)), meaning that countries having trodden some path are facing substantial costs in changing to a significantly different composition. Important voluntary changes in the energy mix imply considerable financial costs, and may be so pronounced that we observe inertia and stable compositions over comparatively long periods such as in the cases of Malta, Cyprus or Poland. ${ }^{3}$

Changes in the energy mix may be driven by natural market forces, such as the supply cost of competing resources on one hand (Chabrol, 2016), or by political decisions including subsidies or government ownership (German Energiewende, France's deployment of nuclear power in the 1970s) on the other hand. Accordingly, these changes

\footnotetext{
${ }^{1}$ The extent to which energy import dependent countries' energy consumption mix differs from their production mix depends on many factors, including national income, geography, existing infrastructure, and other market factors. 2 Primary energy consumption is defined in our study as the IEA (2014)'s TPES measurement, calculated as indigenous production + imports - exports - international marine bunkers - international aviation bunkers +/- stock changes. 3 While most countries take advantage of biomass and conventional fossil fuels, the deployment of geothermal energy, solar \& wind or nuclear energy is still limited. On the other hand the extent to which certain energy forms are deployed, may also vary considerably. France for example covered $42 \%$ of its primary energy consumption from nuclear energy in 2010, while Malta used oil to meet $99 \%$ of its energy demand. Poland relies heavily on its indigenous coal, while Norway is a leading country in exporting North Sea Oil, yet has at the same time abundant hydro-reserves. Obviously, any energy mix will be influenced by both domestic endowments and external supply availability.
} 
may take place slowly as countries become richer (Tahvonen and Salo, 2011; Burke, 2013), or policies may cause abrupt modifications in the energy mix, such as the German phase-out of 8GW of nuclear power in 2011. Such changes may lead to a relatively sudden substitution by new energy carriers, or to a gradual substitution by one, few or many other energy carriers, allowing for differential strategic diversification.

The growing importance of national energy security ${ }^{4}$, including energy supply and consumption diversification, in the face of potential supply disruptions since the first oil crisis (Yergin, 2006), coupled with the desire for cleaner, more efficient and safer energy forms (Burke, 2013) may also drive such transitions and increase the share of certain energy forms in the mix. Currently, EU member states intensify their quest to contribute to environmental protection, climate change mitigation and energy supply security simultaneously, even though Stramboa et al. (2015) note that there are as many inconsistencies as there are synergies in these policies. If we would like to analyze the viability of these ambitious EU plans, it is necessary to generalize experiences about energy paths across both time and countries. ${ }^{5}$

Therefore we investigate the patterns of energy mix changes and energy carrier transitions in the member states of the European Union between 1971 and 2010 using a model based clustering analysis of the European Union's energy mix. The objects of our cluster modeling approach are not countries, but country-years. The novelty of the method, which--to the knowledge of the authors--has not been applied to the problem before allows us to identify distinctive energy profiles (represented by clusters) over time and across the EU, and to trace the dynamics of the movements (trajectories) of countries across these energy profiles, including the presence of possible path dependencies. We also examine whether the data structures discovered by a machine learning algorithm support existing theories of energy transitions and the energy-GDP relationship, or not.

We find seven typical clusters based upon what combination of energy carriers dominate the primary energy mix of a country, which we rank from the highest fossil fuel clusters (meaning that the share of coal, oil and natural gas in energy consumption is the highest) towards the lowest fossil fuel clusters. We find that over the examined period and in the absence of path dependencies countries tend to take a trajectory towards higher quality energy profiles. We also find that higher-quality energy mixes are associated with higher national income per capita and energy use per capita, supporting some evidence on the existence of a national-level energy ladder. We observe beta convergence in energy intensity, and clear path dependencies caused by high indigenous resource endowments.

This paper is structured as follows: Section 2 introduces the current literature, in section 3 we introduce our data, hypotheses and the underlying methodology of model based

\footnotetext{
${ }^{4}$ Already at the beginning of the 20th century, Winston Churchill claimed that "safety and certainty in oil lie in variety and variety alone" (Yergin, 2006). The diversification of the energy mix, and the reduction of energy import dependency (especially from a single supplier) has been an important political goal in the European Union. Diversification as a strategy can be applied to the entire energy portfolio-leading to decreased dependence on one specific form of energy, or to the choice of suppliers (Jewell, 2011). Jewell (2011) among others notes the importance of political stability in the supplying countries, and the sufficient number of entry points and suppliers.

5 With its clear goals to enhance secure and sustainable energy systems, and to combat global climate change, the European Union's 2030 Framework for climate and energy defined three major targets, including a 40\% decrease in greenhouse gas emissions compared to the 1990 levels, a minimum of $27 \%$ share of renewables in energy use, and a $30 \%$ increase in energy efficiency compared to business as usual. The European Commission estimates that the cost of meeting these long-term goals will not significantly differ from the costs that would be needed to replace older energy technologies at the end of their life-cycle (European Commission, 2014a).
} 
clustering, in section 4 our results are presented, while section 5 concludes and presents our policy implications.

\section{Background and Theory}

What are typical energy paths and what determines the trajectories countries take as they develop? Is there an evidence of an energy ladder, defined as a gradual transition to higher quality fuels, as nations become richer? What steps do nations take to diversify their energy mixes? The answers to these questions are of crucial importance in determining the right policies to combat climate change and to enhance energy security. Besides the historical energy transitions referring to entire "eras" such as the "coal era" of the $19^{\text {th }}$ century or the transition to crude oil at the beginning of the $20^{\text {th }}$ century, the energy ladder concept allows us to investigate the short and mid-term dynamics and patterns of national energy mixes.

The concept of a national energy ladder may be summarized as follows: low income, developing countries tend to rely heavily on biomass energy, including wood and charcoal for cooking (IEA, 2013; Burke and Dundas, 2015). As countries become richer, new technologies enter the market, and they substitute towards higher quality energy sources (Csereklyei et al., 2016). Based on empirical findings by Burke (2013), the ladder proceeds from biomass, hydro, oil, coal, natural gas, and nuclear energy to geothermal, waste and wind energy ${ }^{6}$. During this process, as energy consumption in total is growing, the absolute amount of fuel inputs may not decrease, only their share in the energy mix are changing (Csereklyei et al., 2016). Arising from this dynamics, Pearson and Fouquet (2012) note that even a major transition to low-carbon technologies might not warrant a reduction in world fossil consumption.

Currently there are few empirical studies investigating the macro-level presence of an energy ladder. The most comprehensive study covering 134 countries between 1960 and 2010 is that of Burke (2013), who finds empirical evidence for the presence of a "national-level energy ladder" with the increase of per capita GDP. While Csereklyei and Stern (2015) find the role of fossil fuel resources ceteris paribus significant in increasing energy per capita growth in a dataset covering 93 countries over 40 years, Burke (2013 \& 2010) notes the importance of national resource endowments in shaping the transitions on the energy ladder. Countries with large endowments are found less likely or slower to climb to the upper rungs of this ladder. Fossil-fuel rich counties are thus less likely to utilize nuclear power, and modern renewables (Burke, 2013). Larger own indigenous resource endowments may also become the basis of an energy security strategy. Burke (2013)'s findings are also consistent with earlier evidence from Burke (2010) ${ }^{7}$ and Tahvonen and Salo (2001).

The joint implications of these findings are not only that countries with own fossil fuel endowments have a higher than average increase in energy use, but also that they are less

\footnotetext{
${ }^{6}$ Burke (2013) finds that parallel with economic development countries transition "from biomass towards commercial fossil fuels, and hydroelectricity. At higher income levels, countries increasingly adopt low-carbon energy sources such as nuclear power and certain modern renewables such as wind power."(Burke 2013: p500)

7 Burke (2010) provides on the one had empirical evidence for the presence of an "electricity ladder", on the other hand presents a simple stylized model of income, resources and the electricity mix, providing an analytical framework to explain historical patterns.
} 
likely to transit to cleaner energy forms. Nuclear energy and renewables, both requiring large capital investments and economies of scale are found at the upper part of the energy ladder (Burke, 2013). At the same time, the carbon emissions from these energy forms are already declining. The energy profile of a country therefore explains large variations in emissions among different countries (Marrero, 2010). Burke (2013) proposes three potential reasons for the presence of a national-level energy ladder. The first factor is the reliance on indigenous energy sources with diminishing returns, meaning that imported fuels are gradually becoming more cost-competitive as own natural resources are becoming increasingly scarce (Burke, 2013; Tahvonen and Salo, 2001). The second reason is found in the positive income elasticity for more efficient and clean energy forms as societies get richer, and lastly sectoral and structural changes may also contribute to the appearance of a national-level energy ladder, along with the shift from an industrial to a more service oriented economy (Judson et al., 1999).

Taking a different approach, the concept of energy ladder has been studied more extensively from a micro-economic view on the household level (e.g. Hosier and Dowd, 1987; Heltberg, 2004; Hosier, 2004; van der Kroon et al., 2013), and on the firm level (Bousquet and Ivaldi, 1988). Heltberg (2004) finds that growing incomes on a household level, together with the relative fuel prices are the determining factors for the speed with which households switch fuels and move up the electricity ladder. However, in their metaanalysis, van der Kroon et al. (2013) cannot observe the energy ladder empirically. They claim a linear pattern of fuel displacement at higher income levels, and multiple fuel use representing an energy portfolio, which they call energy stacking behavior. The presence of this fuel stacking behavior in household energy transitions is also supported by Burke and Dundas (2015), who find evidence from a 175 country panel between 1990-2010 that female labor force participation is associated with the reduction of biomass use. At the same time increased income per capita seems to lead to an increased use of higher quality fuels, but it is not significantly associated with the reduction of biomass energy use.

From the viewpoint of energy security, countries with indigenous resource endowments may choose to predominantly rely on these resources, and thus may get "locked in" at a lower part of the ladder. Such lock-in effects cause path dependencies. On the other hand, countries without the necessary fossil fuels to cover their energy demand may transition to renewable energies faster, as renewable energy sources - arising from their local nature, are inherently energy secure. Another aspect not covered by the concept of the energy ladder is the notion of infrastructural lock-in (Sovacool, 2016) relating to plant infrastructure, grid-topography, ports, pipelines and supply routes. Existing pipeline systems may increase the dependency on transported oil or gas, and the same grid-system that is perfect for nuclear energy is suboptimal for integrating renewables. In our study we will extend our analysis of the energy ladder and also examine the impact of natural resource endowments and infrastructure in causing path dependencies.

Departing from the income driven concept of an energy ladder, energy transitions in a historical context may take a very long time, spanning decades or centuries (Gales et al., 2007; Grübler et al., 1999; Fouquet and Pearson, 2012; Grübler, 2004; Grübler, 2012; Rubio and Folchi, 2012). Fouquet and Pearson (2012) define energy transition as "the switch from an economic system, dependent on one series of energy sources and technologies to another." While the patterns and dynamics of energy transitions are well known, the speed and the timing of these can be very distinctive (Grübler, 2012). While it is usually accepted that energy transitions take a long time, Sovacool (2016) presents 
some counterevidence both for end-use devices and for transitions in supply. One important stylized fact of energy transitions is the continuously increasing energy quality (Stern, 2010) and energy efficiency (Stern, 2012). ${ }^{8}$

Past energy transitions were not only driven by technological change, but also by resource availability, energy demand, and most importantly government policies and institutions (Fouquet and Pearson, 2012; Gales et al., 2007). Further determinants include trade relations (Rubio and Folchi, 2012), the role of policy and of incumbent governments (Fouquet and Pearson, 2012). Fouquet and Pearson (2012) find that successful energy transitions in the past were characterized by lower costs for the new technology and the new energy source than for the previously dominant energy source. This implies that new sources only diffuse widely, when they become sufficiently cheap to compete on the market.

Grübler et al. (1999) developed a long-term model of energy transitions based on technology saturation and energy technology choices. They find that the replacement of long-lived infrastructures went hand in hand with the replacement of energy forms, leading to a decarbonisation of the primary energy supply with about $0.3 \%$ per year. Their model is based on endogenous technical choices, and S-shaped (logistic) diffusion patterns incorporating learning phenomena on a macro-scale. In a later study, Grübler (2012) claims three major insights from energy transitions research. These include the role of energy end-use driving energy transitions, and the slow pace of such transitions. He also finds that the timing and speed of transitions have been very different in Europe, and claims the presence of distinct patterns in the successful diffusion of technology systems. Most importantly, the persistence and continuity of policies are deemed as the key for this success, as energy transitions take long, and at the same time technological knowledge depreciates very fast. Erratic policies can easily fail to trigger the expected outcome.

All of the above insights on energy transitions and ladders further highlight the importance of proper policy measures to actively manage the transition towards lowcarbon sources. Gross et al. (2009) note that investment conditions created by policies will significantly impact on the success of energy technologies. Schaffer and Bernauer (2014) report that renewable policies such as feed-in-tariffs (FiT) have drastically increased the use of renewable sources in power generation in Germany between 2000 and 2008. However, significant challenges to clean-energy transitions are also arising from the economic viability of renewable energy. Increased renewable generation may result in strongly falling prices on the electricity markets, which might in turn decrease the value of renewables (Hirth, 2015). Hirth (2015) claims that because of this, long-term subsidies might be needed to ensure broad-deployment.

Therefore, studying the dynamics of natural energy transitions and their policy implications is of crucial importance for future energy concepts. While a number of studies exist on general energy transitions (Grübler et al., 1999; Fouquet and Pearson, 2012; Grübler, 2004; Araujo, 2014; Sovacool, 2016) and on the energy ladder (Burke

\footnotetext{
${ }^{8}$ Csereklyei et al. (2016) investigate the stylized facts of energy and economic growth for 99 countries over the past 40 years. Their findings indicate a stable relationship between energy use per capita and income over the past decades, a convergence in energy intensity and income per capita over the past two centuries, a declining energy/capital ratio with increasing income and over time, and a decline in the cost share of energy over time. They also find increasing energy quality with income, consistent with the energy ladder hypothesis.
} 
2010 \& 2013), to our knowledge our study is the first one addressing these dynamics with model based clustering methods, and extending the concept of energy trajectories with energy security implications.

\section{Data and Methods}

\subsection{Data}

Our analysis is based on an unbalanced dataset of the 28 countries of the European Union covering the period 1971 to 2010 . Our main variable is the primary energy mix ${ }^{9}$ (energy carrier composition) over this period. We define the primary energy mix as the combination of eight different energy forms, which make up the total primary energy consumption: biomass, coal, oil, natural gas, nuclear energy, hydro-energy, renewables, and others. ${ }^{10}$ The sum of the shares of these energy carriers in energy consumption adds up to one. The IEA (2013) aggregates under traditional biomass fuelwood, charcoal, animal dung and agricultural residues in stoves, most of which are used with very low efficiencies (Csereklyei et al., 2016). Biomass therefore is usually found at the lower ranks of the energy ladder (Burke, 2013). ${ }^{\mathbf{1 1}}$ Trade and final consumption from "heat" and "electricity" included negative values due to exports. These trade flows are captured by the category "others". This category sums up on average (over countries and time) to $0.6 \%$ of primary energy consumption. Data for the entire observation period is available for 23 countries, in case of Estonia, Latvia, Lithuania, Slovenia and Croatia the IEA energy data starts only in 1990.

Additional indicators, used for external validation include population and purchasing power adjusted real GDP per capita between 1971 and 2010 from the Penn World Table 7.1 (Heston et. al., 2012). The energy security variable (energy import as \% of energy use) originates from the WDI database (World Bank, 2015). Indigenous resource endowments were sourced from Burke (2013).

\subsection{Methods: Model Based Clustering}

We use model based clustering of country-years to investigate energy paths and profiles in the European Union. Traditional time series clustering (Liao, 2005) has been applied to various areas of life and science (Aghabozorgi et al., 2015), including energy data.

Among others, Iglesias and Kastner (2013) investigated building energy patterns, and Hsu (2015) presented a comparison of several clustering methods to predict energy consumption data. Different clustering techniques have been also used for electric power system load forecasting (Duan et al, 2011), outlier detection in building energy consumption ( $\mathrm{Li}$ et al. 2010), wind-speed forecasting (Liu et al. 2015), and environmental damage assessment in marine ecological environment (Yang, 2015). While the application of clustering methods, and especially model-based clustering is relatively new

\footnotetext{
9 Primary energy consumption is defined in our study as the IEA (2014)'s TPES measurement, calculated as indigenous production + imports - exports - international marine bunkers - international aviation bunkers $+/$ - stock changes. As mentioned earlier we work with the composition of primary energy consumption as this includes potential exports and imports and the connected energy choices.

${ }^{10}$ We, therefore, grouped together some of the energy sources as follows: "Oil” is the sum of "crude, NGL, and feedstocks" and "oil products". "Coal" is the sum of "coal" and "peat". The "Renewables" category includes heat and primary electricity gained from "geothermal energy", and from "solar \& wind”.

${ }^{11}$ Even though highly advanced methods appeared in the past years in developing countries to process biomass, their use is not widespread yet, and thus non-sufficient to change our category of biomass as "low-quality" energy form.
} 
in energy economics and policy, machine-learning algorithms are becoming an increasingly popular way to address profiling and forecasting problems.

The underlying idea of any clustering technique is to group high-dimensional objects, which are measured along several dimensions into meaningful groups (Ahlquist and Breunig, 2012). Our variable of interest is the primary energy mix of the 28 member states of the European Union between 1971 and 2010, as described in the data section. Therefore the unit of observation is the energy mix of country " $i$ ", in year " $t$ ", or countryyears. We analyze the composition of these energy mixes, and whether they can be grouped into clusters over cross-sections and time. Countries may stay in the same cluster over the entire observation period, or move up or down across the clusters. We call this behavior their "energy path".

Model based clustering belongs to the category of unsupervised learning algorithms, and has its foundations in probability theory. Unsupervised learning methods are able to determine the shape and the number of clusters that optimally describe and confirm the structure of the underlying data (Ahlquist and Breunig, 2012). The discovery of meaningful structures by means of unsupervised learning can be then used to evaluate theoretical expectations about the nature and dynamics of the data. Based on these methodological properties, we argue that using model based clustering is a novel and interesting method in examining the energy paths of nations. Ahlquist and Breunig (2012) note that as the number of dimensions relative to the number of observations is increasing it becomes increasingly difficult to identify general patterns in the data, or to identify the existence and the shape of clusters. As we work with $k=8$ dimensions comprising of the different energy carriers, and n=1025 country-year observations, identification in our case is not a serious problem. While it is possible to group unrelated concepts such as energy mixes or endowments together, for the purpose of this study we were interested purely in the changes in the energy mix, and in the validation of energy ladder and transition theories.

The clustering algorithm is applied simultaneously to the entire dataset, therefore the clusters are created with all observations ("country-year" values) being considered at once. Because of this, the clusters represent the "same concept" over the successive years. This is also the reason why the problem of missing country-year observations resulting from an unbalanced panel is not significantly affecting the validity of the results. The main purpose of our approach is thus to derive clusters, which are stable over time. Stability here refers the accumulation of similar country-year observations that define a cluster. This does not mean that countries have to stay in a cluster, but that enough countries pass through a given composition (cluster) in time, hence a large number of country-year points can be assigned to form a specific composition. Changing the cluster membership over the years therefore reflects the time series aspect of the analysis.

For the purpose of our analysis we assume that the data is generated by mixture models ${ }^{12}$ (Fraley and Raftery 2005; Raftery and Dean 2006), enabling a so-called “soft-clustering” procedure. Soft clustering implies that the probabilities for an observation (country "i” at

\footnotetext{
12 In case of mixture models, the data generation process (DGP) is assumed to be given by some finite mixture of probability distributions, where $x=\left(x_{1}, \ldots, x_{n}\right)$, is an $n \mathrm{x} k$ matrix of " $\mathrm{n}$ " objects measured on " $\mathrm{k}$ " dimensions. This implies that the density of $x$ will be given by a mixture of the form $f(x)=\sum_{g=1}^{G} q_{g} f_{g}(x)$, where $\mathrm{G}$ is the number of mixture components, and $q_{g}$ is the proportion of objects in a component g, and $f_{g}(\cdot)$ is the density function for observations in component $g$ (Ahlquist and Breunig, 2012).
} 
time period " $t$ ") of being in a specific cluster at a certain point in time are computed and weighted. Models with different covariance structures are allowed and thus we are able to accommodate different cluster shapes and sizes, varying in volume and direction. We assume a multinormal ${ }^{13}$ distribution for the variables with cluster specific parameters $\left(\mu_{g}, \Sigma_{g}\right)$. The assignment of an observation to a cluster is modeled by a multinomial distribution, for details, see Ahlquist and Breuning (2012). ${ }^{14}$ One potential concern that has to be noted in connection with the approach is the potential autocorrelation of the shares of energy forms in one country over time, which violates the basic assumption of observational independence. Since we are only interested in classification, this issue should not influence the interpretability of our conclusions.

It has to be noted that using Gaussian models, the model based clustering algorithm identifies spherical or ellipsoid shaped clusters, yet fails to identify line shaped or rectangular clusters. Despite the fact that the variables of the energy mix are themselves not always normally distributed, a cross-variable plot of the data shows in Figures 1a and $1 \mathrm{~b}$ that the ellipsoidal clustering assumption is still valid, and as a consequence the Gaussian distribution assumption is a good approximation. Assuming that clusters follow a certain model type, model based clustering searches for the optimal shape and number of clusters, given the structure of the data.

In our study, we defined eight dimensions corresponding to share of the energy carriers making up the national primary energy consumption mix. Fitting the model via expectation maximization ${ }^{15}$ (EM) (Ahlquist and Breunig, 2012; Dempster et al., 1977) for each parameterization of the covariance matrix $\Sigma_{g}$ might lead to different shapes of the clusters. To avoid the models showing degeneracy, singularities or shrinking components we used a highly dispersed conjugate prior suggested by Fraley and Raftery (2007), and chose the "VVV" initialisation procedure, that places no restrictions on the covariance matrices in the clusters.

\footnotetext{
${ }^{13}$ By assuming multivariate normal densities for all groups, we can substitute $\phi\left(x \mid \theta_{g}\right)$ for $f_{g}(x)$, where $\phi\left(\cdot \mid \theta_{g}\right)$ is the multivariate normal density function with parameters $\theta_{g}=\left(\mu_{g}, \Sigma_{g}\right)$. The density takes therefore the form: $\phi\left(x_{i} \mid \mu_{g}, \Sigma_{g}\right)=(2 \pi)^{-\frac{k}{2}}\left|\Sigma_{g}\right|^{-\frac{1}{2}} \exp \left[-\frac{1}{2}\left(x_{i}-\mu_{g}\right)^{\prime} \Sigma_{g}^{-1}\left(x_{i}-\mu_{g}\right)\right.$. An observation would be classified being in a group g, if $\tau_{g}(x)>\tau_{h}(x), \forall h \neq g, h \in 1, \ldots, G$, where $\tau_{g}(x)=\frac{q_{g} \phi\left(x \mid \theta_{g}\right)}{\sum_{h=1}^{G} q_{h} \phi\left(x \mid \theta_{h}\right)}$ in which case, $\tau_{g}$ is the posterior probability that an object belongs to group "g” (Ahlquist and Breunig, 2012).

${ }^{14}$ All calculations were done with R’s “mclust” package version 5.2 (Fraley et al., 2012; Fraley and Raftery, 2002).

15 The process of fitting the model treats the actual cluster to which observation $i$ belongs as missing data. The complete dataset, $y_{i}$ is denoted by $\left(x_{i}, z_{i}\right)$, where $x_{i}$, represent the observed data, on which we have to fit the clustering model and $z_{i}$ is a $G$-vector of the $g$ th element, which takes on the value of 1 iff $i$ belongs to cluster $g$ and 0 otherwise. By assuming that $z_{i} \sim$ multinorm $\left(\tau_{1}, \ldots, \tau_{G}\right)$, the "complete data" likelihood can be given by: $L_{c}=\prod_{i=1}^{n} \prod_{g=1}^{G}\left[\tau_{g} \phi_{g}\left[x_{i} \mid \theta_{g}\right]\right]^{Z_{i g}}$. The EM procedure begins with the "maximization-step", in which the likelihood function is maximized with respect to $\left(\tau_{1}, \ldots, \tau_{G} ; \theta_{1}, \ldots \theta_{G}\right)$, holding $\mathbf{z}$ at $\tilde{z}$. With the initialized responsibilities held at $\tilde{z}_{i g}$, the estimated parameters in the maximum likelihood step are now used to update the hidden variable $\tilde{z}_{i g}$. Therefore, the initial cluster assignments of the hierarchical clustering change. This step is called "expectation-step". With this new assignment the inferred parameters also change. Each "e-step" follows another "m-step" and vice versa until the algorithm converges. Initialization assumptions refer to the estimation of the hidden variable $\tilde{z}_{i g}$ or its assignment to a cluster, since the responsibilities $\tilde{z}_{i g}$ can only be calculated after the first m-step. Therefore to "kick-off" the EM algorithm an initialization responsibility is needed. We use model-based Gaussian hierarchical clustering to initialize $\tilde{z}_{i g}$.
} 


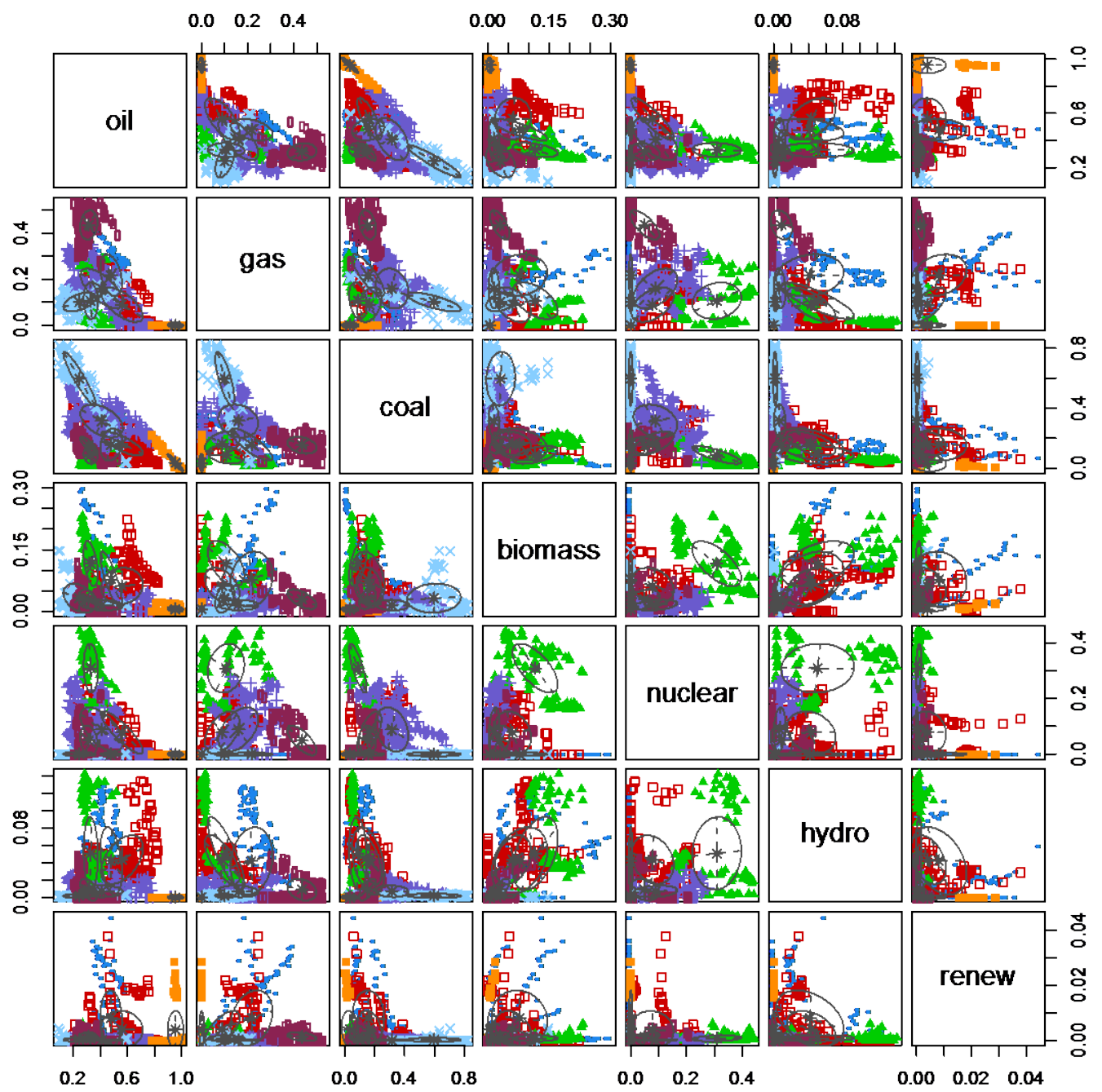

Figure 1a. Cross variable plot of the cluster dimensions: We show scatterplots of the shares allocated to each energy type. Note that the scaling differs due to better readability. 


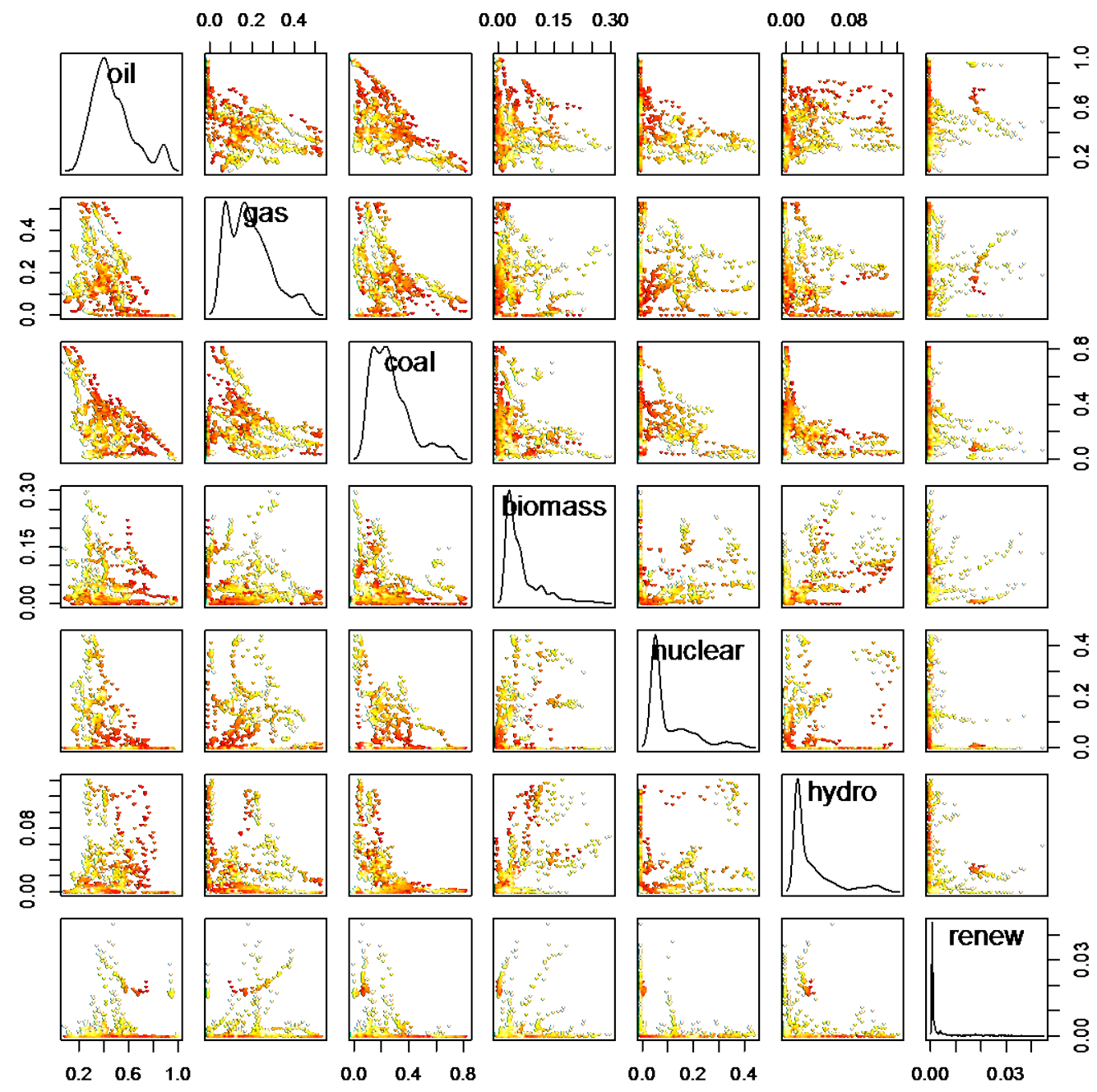

Figure 1b. Cross variable plot of the cluster dimensions: We show the time dimension of the scatterplots with red marks denoting observations in 1971, proceeding towards yellow in 2010. Note that the scaling differs due to better readability.

The "VVV" algorithm assumes that the data follows a multivariate Gaussian distribution and places no restriction on cluster size, orientation or volume. In every step the total change in the likelihood resulting from the merging of two clusters is calculated. The merge leading to the highest likelihood will be applied. As noted previously the algorithm is applied to all observations simultaneously. In determining the optimal number of clusters, we used both the Elbow criterion, as suggested by Ahlquist and Breunig (2012) and a modified BIC criterion. Dziak et al. (2012) suggested adjusting the penalty term of the BIC criterion. As the BIC criterion does not penalize the number of clusters in a sufficient manner, we have set the penalty for the adjusted BIC the following way:

$$
A B I C=2 \log L\left(x, \hat{\theta}_{G}\right)-3 m_{G} \log n
$$

Figures 2 and 3 show the optimal number of clusters selected based on the adjusted BIC and the Elbow criterions, both at seven clusters, or seven distinctive energy profiles. This means that seven clusters best explain the structure of the data, after penalizing for the number of clusters. 


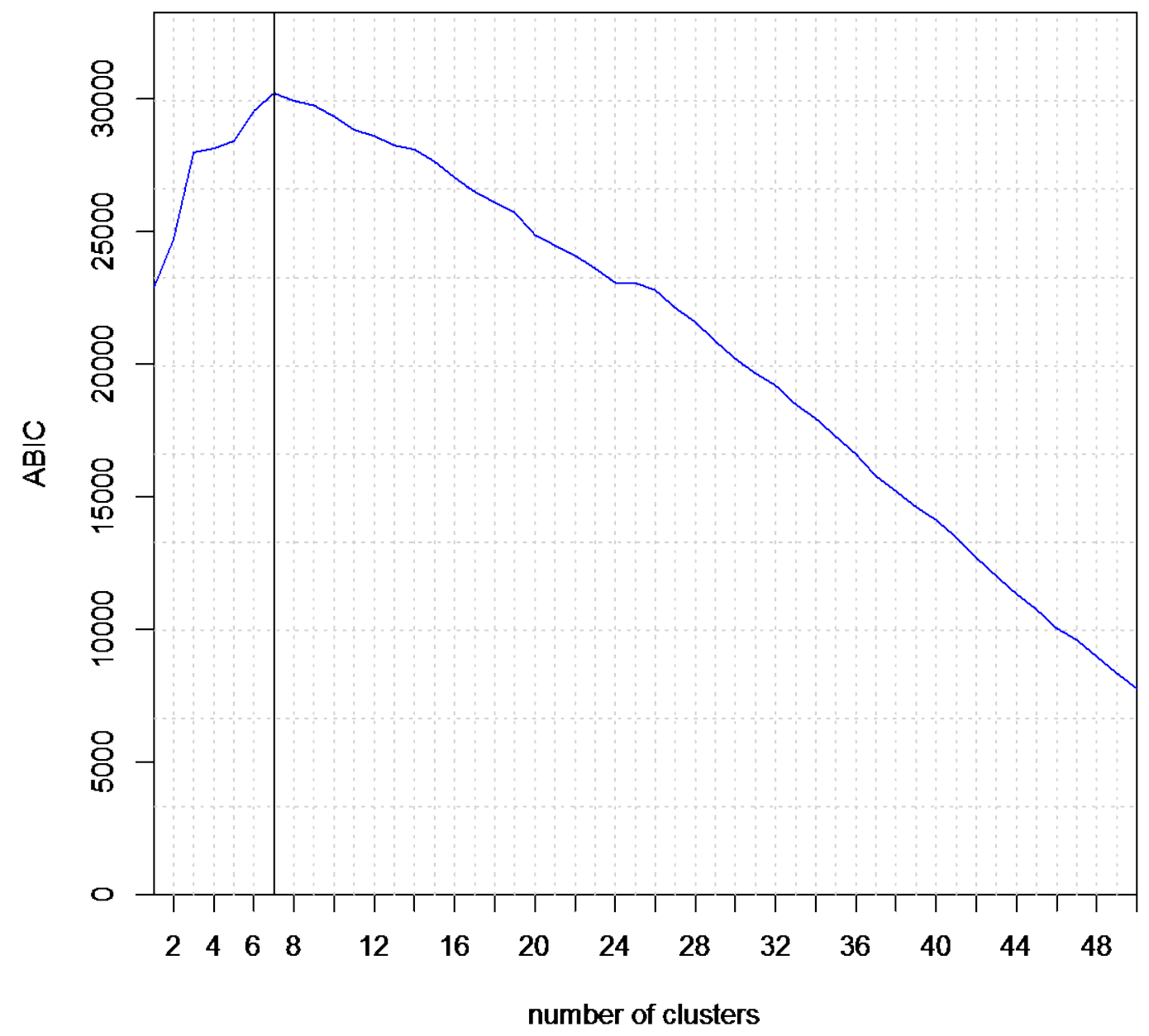

Figure 2. Optimal number of clusters based on the adjusted (negative) BIC criterion: The selection criterion was defined as: $-A B I C=-2 \log L\left(x, \hat{\theta}_{G}\right)+3 m_{G} \log n$. 


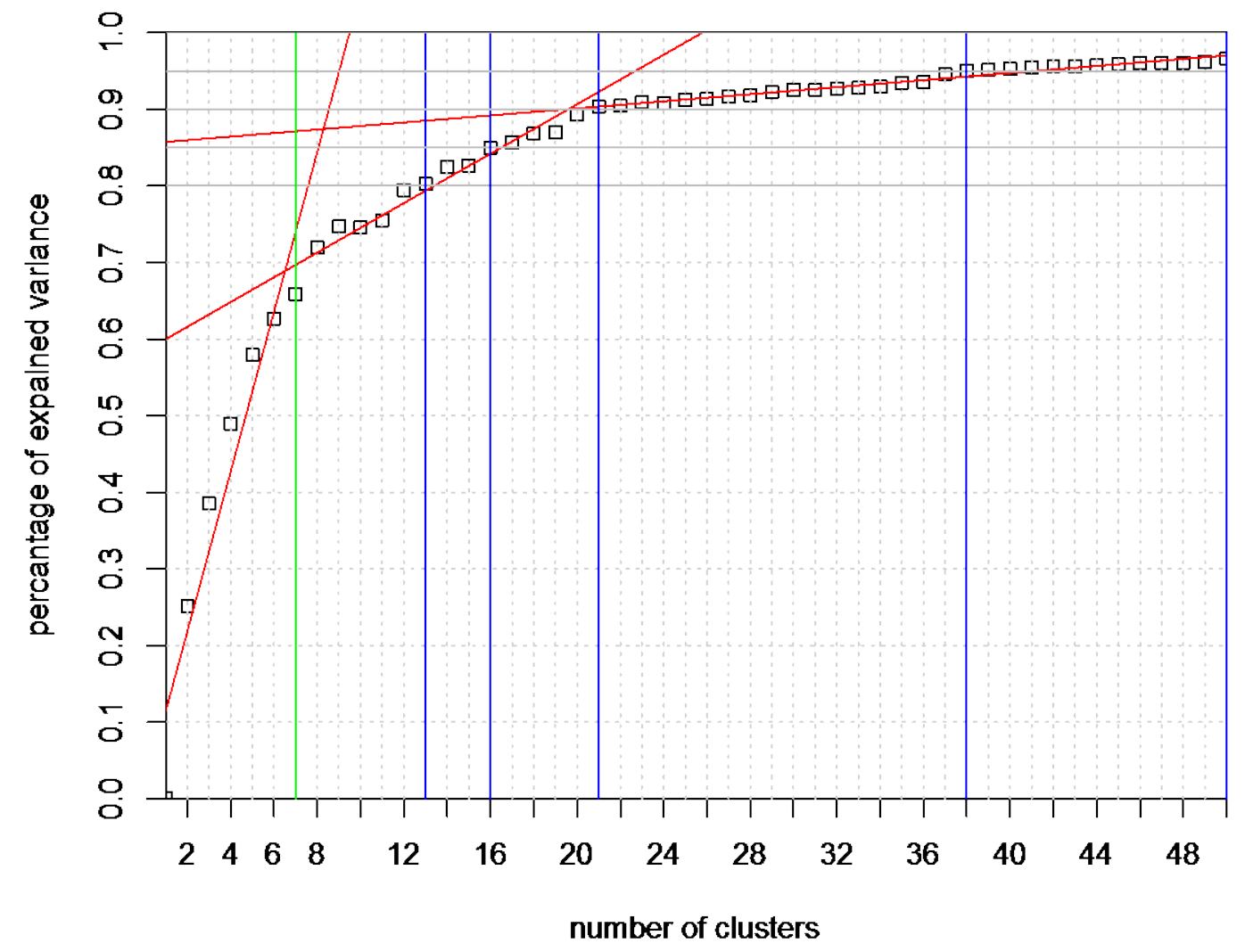

Figure 3. Optimal number of clusters based on the Elbow criterion

Ahlquist and Breuning (2012) argue that unsupervised learning is a useful tool in evaluating theoretical claims, based on whether or not meaningful structures and patterns consistent with the theory are found in the data. Hence, the main rationale behind the usage of machine learning algorithms is to seek and infer such patterns and structures, without prior classification. Several theoretical concepts have been introduced in the previous section about energy transitions and the energy ladder. Therefore, we would like to test whether the composition of the seven identified clusters exhibit specific properties, and whether countries embark on certain paths over time, and then validate these patterns against economic theory.

\section{European Energy Paths and Strategy}

\subsection{Energy Profiles and Paths}

This section analyzes the development of the energy mixes of the European Union member states, with special emphasis on path profiles and dependencies. Specifically we seek evidence for the presence of a national energy ladder, endowment lock-in effects (Burke 2010 \& 2013), for the theory of increasing energy quality with income (Csereklyei et al., 2016), and a possible convergence in energy intensity as national energy policy (EC 2013 \&2014a) and technological levels converge over time (Csereklyei et al., 2016). The overall composition of the selected clusters represent specific energy profiles or a characteristic mix of primary energy carriers. Since countries may switch clusters, or 
profiles over the examined period, the number and combination of countries in a certain cluster does not stay constant. The identified clusters, their energy mix composition, and the standard errors are found in Table 1.

\begin{tabular}{|l|r|r|r|r|r|r|r|}
\hline \multirow{2}{*}{ Type } & & & & & & & \\
& Cluster.7 & Cluster.6 & Cluster.5 & Cluster.4 & Cluster.3 & Cluster.2 & Cluster.1 \\
\hline Gas & 95.4 & 24.7 & 31.6 & 41.1 & 48.0 & 56.0 & 33.0 \\
& 5.8 & 11.9 & 6.3 & 15.6 & 8.0 & 15.4 & 5.2 \\
\hline Coal & 0.0 & 10.1 & 43.5 & 16.0 & 21.7 & 8.9 & 10.6 \\
& 1.1 & 4.1 & 6.4 & 8.6 & 9.1 & 7.5 & 7.9 \\
\hline \multirow{3}{*}{ Biomass } & 3.7 & 59.7 & 15.4 & 31.6 & 15.7 & 16.5 & 8.9 \\
& 5.7 & 17.9 & 5.6 & 11.0 & 10.7 & 8.0 & 5.9 \\
\hline Nuclear & 0.5 & 3.2 & 2.9 & 1.5 & 7.8 & 6.2 & 11.6 \\
& 0.7 & 3.5 & 2.4 & 1.3 & 6.8 & 4.4 & 5.5 \\
\hline Hydro & 0.0 & 0.0 & 5.0 & 8.9 & 0.0 & 7.8 & 30.9 \\
& 0.0 & 0.7 & 5.3 & 7.9 & 0.6 & 7.6 & 8.8 \\
\hline Renew & 0.2 & 0.2 & 0.9 & 0.7 & 4.2 & 4.3 & 5.1 \\
& 0.4 & 0.0 & 0.1 & 0.0 & 0.8 & 0.4 & 0.1 \\
& 0.7 & 0.1 & 0.2 & 0.0 & 1.0 & 0.7 & 0.1 \\
\hline
\end{tabular}

Table 1: Energy Profiles of the European Union 1971-2010

Table Notes: the energy mixes were defined as the ratio of oil, gas, coal, biomass, nuclear, hydro and renewable energy. The group excluded for the purpose of calculations included electricity exports and imports, that were not otherwise classified into energy carriers. Standard deviations are found in italics.

The shares allocated to each energy carrier in our clusters are an average over time and across countries, in a given cluster. An energy-profile is formed by specific country-year observations getting assigned to a cluster across all data points. The standard deviations show that the clusters are relatively stable, which can be understood as a high number of observations of characteristic combinations of energy shares that countries exhibit, or have exhibited at some point in the past, when passing through that cluster. These profiles can be understood as rungs towards a higher quality energy mix.

We number the clusters identified by our machine learning algorithm from 1 to 7 based on the combined share of fossil fuels in the energy mix, including coal, oil and natural gas. High fossil-fuel clusters carry a higher number. The reason for this is that fossil fuels make up the majority of primary energy supply, and we would have liked to trace how countries substitute (or not) between different energy forms, and whether we observe as expected a transition away from fossil fuels towards higher "rung" energy forms (Burke, 2013). Countries however may not transition towards a lower-fossil fuel profile, or do so very slowly due to endowment effects (Burke, 2013). Our method therefore allows for the detection of path inertia (Sovacool, 2016), indicated by the same profile throughout the observation period, as well as for potential increase in fossil-fuel dependency.

While we chose to order the clusters based on their combined fossil fuel use, the share of 
oil, gas and coal consumption differ within the clusters. For example cluster 4 has lower total fossil use than cluster 5, but consists of more coal and oil, while cluster 5's composition relies on natural gas and oil consumption. Based on this ordering, the share of fossil fuels drops from $99.1 \%$ in cluster 7 to $52.5 \%$ in cluster 1 . Should countries over time systematically move between clusters, and predominantly move towards lower number clusters, this would indicate the presence of an energy transition towards less fossil fuel use and towards increased renewable and nuclear energy use. 




Table 2: Country-year matrix of cluster occupation 1971-2010 
This would also potentially lead to the diversification of the energy consumption mix - which - in the absence of indigenous resources - is a mayor factor in increasing long-term energy security ${ }^{16}$. Table 2 presents the country-year matrix of cluster occupation over the entire observation period.

Examining the profiles, clusters 7 and 6 seem to be "locked in" in their position with only limited movements to and from these clusters. These profiles are bound with high inertia and path-dependence. Cluster 7 shows the highest fossil fuel consumption with 99.1\%, from that $95.4 \%$ oil, and includes the islands of Cyprus and Malta in 2010, both of which cover the majority of their primary energy consumption with imported oil. For a short period of time between 1973 and 1977, this cluster also harbored Denmark, an oil producer. Cluster 6 is still dominated by fossil fuels, totaling to $94.5 \%$ of the primary energy use, with negligible hydro, nuclear or renewable energy. The main portion of fossil fuel consumption is met by coal. It includes Estonia and Poland in 2010, both of which show very high shares of coal in their national energy mixes over the past forty years. This is not surprising in the light of abundant coal resources in Poland, as indigenous resources not only tend to be cheaper but also more supply secure. Initially also Hungary, the Czech Republic and Luxembourg belonged to this cluster, but these countries transitioned towards less fossil intensive fuel mixes.

Clusters 5 and 4 show similar levels of fossil fuel consumption, with $90.5 \%$ and $88.7 \%$ respectively, however while cluster 5 is dominated by a combination of natural gas and oil, the energy demand is met by oil and coal in cluster 4. Cluster 5 originally included the Netherlands and Romania in 1971 both of which retained their positions, and included additionally Belgium, Hungary and the United Kingdom by 2010, all of which transitioned from cluster 4 . We saw that the main difference between clusters 5 and 4 lies in the composition of the fossil fuel supply. Therefore we see a substitution towards a gas/oil dominated mix from an oil/coal dominated mix. Cluster 4 has evidenced a transition from its 1971 occupants to only Slovakia by 2010.

In cluster 3 the share of renewables, hydro and biomass generation rises as fossil fuel shares begin to decline. Austria, Croatia and Latvia remained in this cluster for the entire period, while Portugal, Italy and Lithuania, moved here from clusters $2 \& 1$, and all other countries from higher fossil fuel clusters. The shift towards higherquality energy forms is further amplified in cluster 2, with an average of $81.4 \%$ dependency on fossil fuels, and a combination of nuclear, biomass, and hydro energy to meet the rest of the demand. Cluster 1 shows a visible transition to non-fossil energy forms including all forms of renewables, hydro and nuclear energy, a combination of which almost covers half of the primary energy consumption. Cluster 2 originally included Finland, France, Greece, Italy, Portugal, Spain and Sweden in 1971. From the original "inhabitants”, Finland, France and Sweden transferred to cluster 1, while Greece, Portugal, and Italy to higher fossil fuel clusters.

In 2012 the EU's energy mix was made up of 32\% oil, 23.9\% natural gas and $17.5 \%$ coal, or a total of $73.4 \%$ fossil fuels (IEA, 2014b). This number is lower than the fossil fuel share in cluster 2. This supports the claim of the IEA (2014b) that alone since 2007, the consumption of fossil fuels declined by $11.9 \%$ in the European Union.

16 Short-term security on the other hand may include the diversification of suppliers and supply routes for the existing mix (Jewell, 2011). 
The IEA (2014b) also notes that the overall EU energy mix is slow to change and individual members have considerably different energy portfolios, depending on their national energy policy and indigenous endowments. Renewable energy accounted for $12.1 \%$ of total primary energy supply in 2012. This was made up from biofuels and waste (8.3\%), hydro (1.8\%), wind (1.1\%), solar (0.6\%) and geothermal $(0.3 \%)$ energy (IEA, 2014b). While the share of renewables has increased from 8\% in 2007, mostly driven by solar and wind deployment, the share of hydro-energy remained relatively stable due to high saturation. Despite the high growth rates in solar and wind power, these energy sources still make up only a minor part of the primary energy supply ${ }^{17}$.

\subsection{National-Level Energy Ladder, Endowment Effects, Energy Intensity Convergence and Energy Security}

To test the energy ladder hypothesis introduced in section 2, we compare the different energy profiles along their income per capita levels and development. Theoretically the highest income per capita levels should be associated with the highest quality energy profiles, and vice versa. Figure 4 depicts the weighted average GDP per capita development of the clusters over time. While the different profiles include characteristic combinations of energy forms, and countries transit between these profiles, systematically it appears that higher energy quality clusters tend to have the uppermost GDP per capita, such as clusters 1 and 2 in 2010. At the same time clusters 6 \& 7 show over the entire observation period the lowest per capita income. These observations would support descriptive evidence on the presence of a national-level energy ladder, even though we do not study the impact of GDP per capita on the different energy sources, but on distinct combinations of these sources.

\footnotetext{
${ }^{17}$ Wind energy is currently the most cost efficient renewable energy source, despite the integration challenges into the power systems due to its intermittency (Duić et al., 2013).
} 


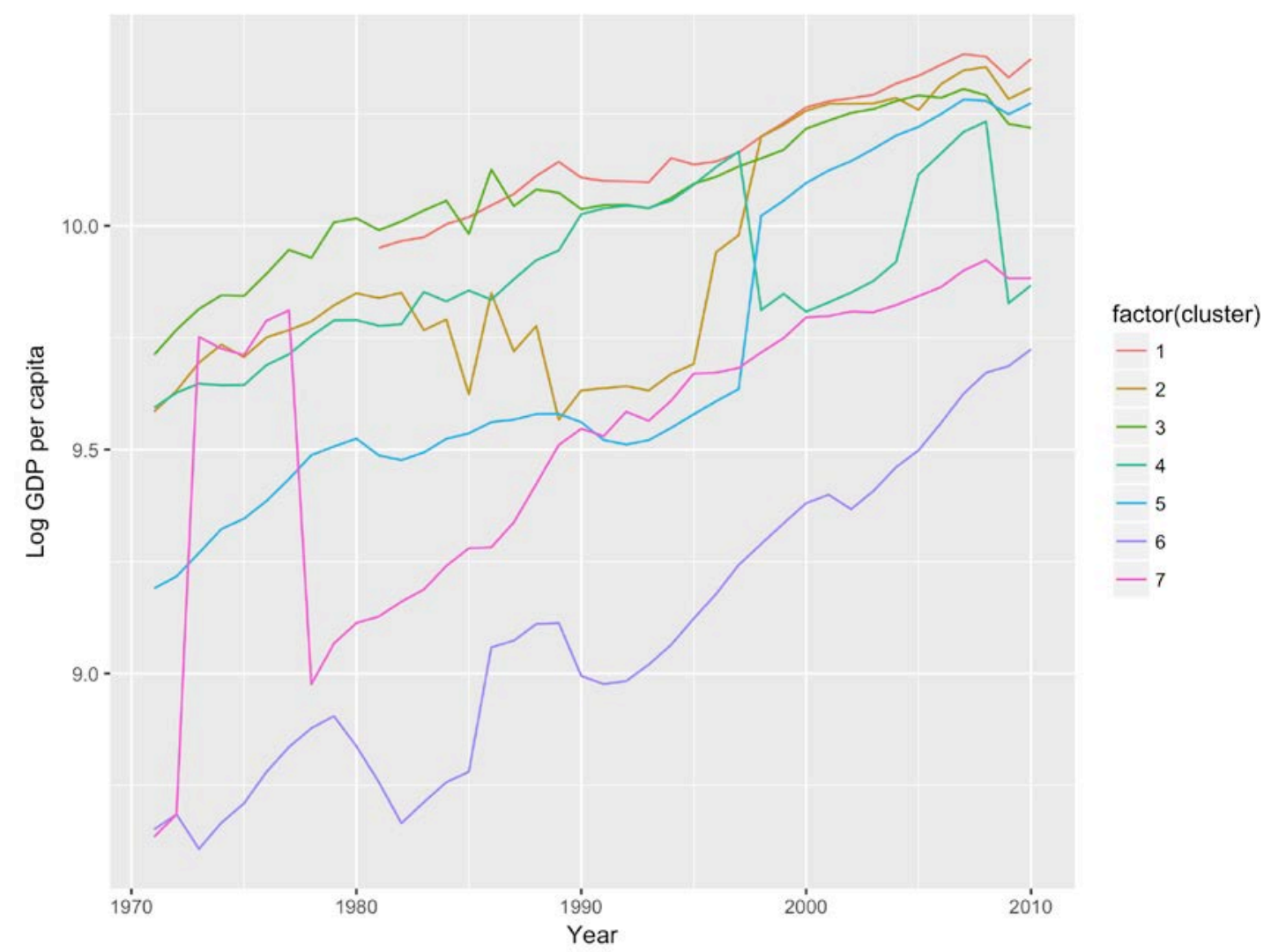

Figure 4. GDP per capita development of the clusters: The log GDP per capita is the population weighted average of all countries in a cluster in a corresponding year. Note that the countries in a specific cluster vary over time.

We also test the claims that high indigenous resource endowments cause path inertia, and countries with high own resources progress slower on the energy ladder. Figures 5 a-e show the weighted average resource endowments per capita development of the clusters, including coal, lignite, gas, and freshwater. We also present forest areas as the percentage of land. 

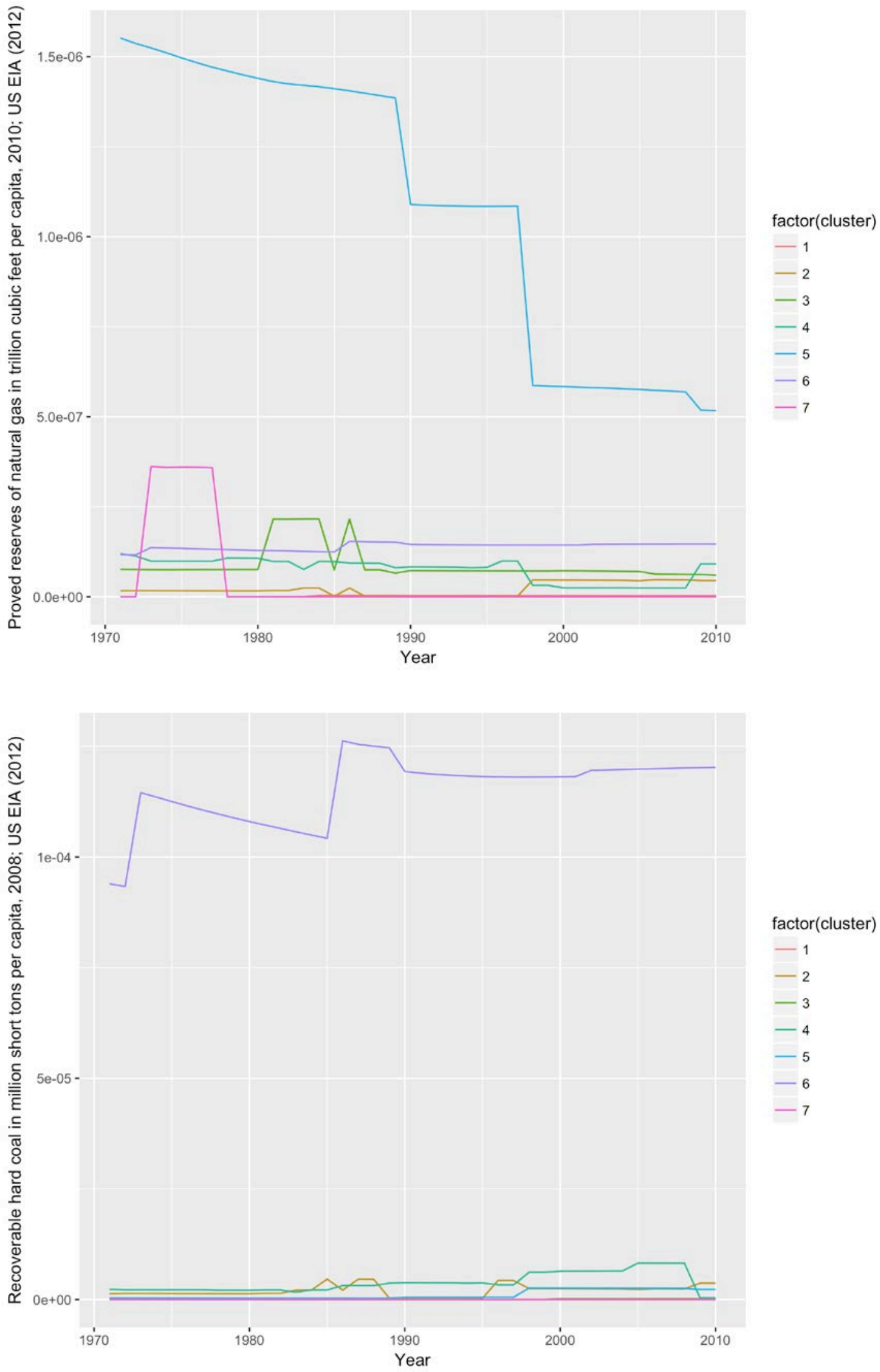

Figures 5 a. and b. Natural gas and hard coal reserves per capita development of the clusters: The reserves per capita are the population weighted average of all countries in a cluster in a corresponding year. Note that the countries in a specific cluster vary over time. 

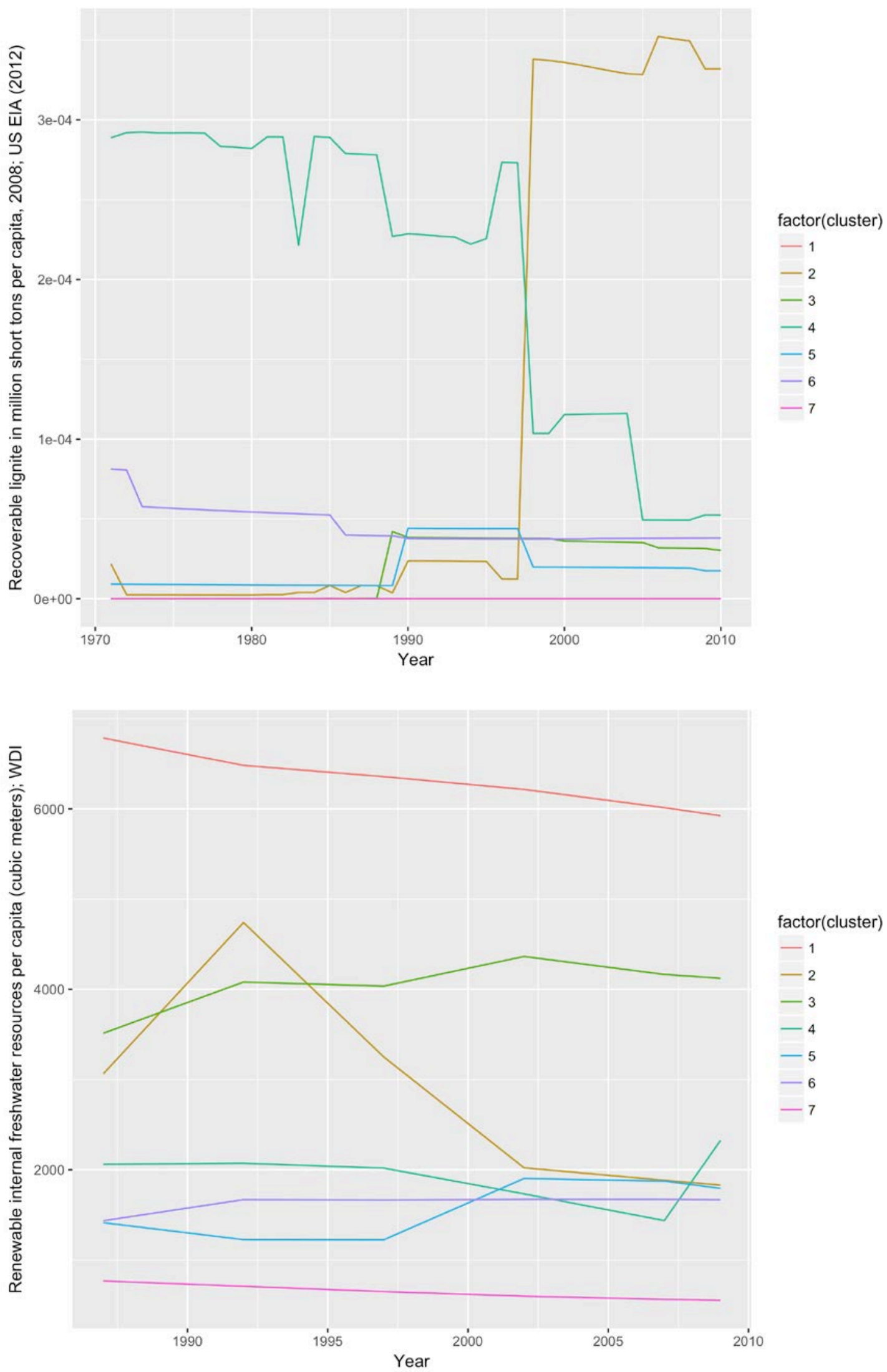

Figures 5 c. and d. Lignite reserves and renewable internal freshwater resources per capita development of the clusters: The reserves per capita are the population weighted average of all countries in a cluster in a corresponding year. Note that the countries in a specific cluster vary over time. 


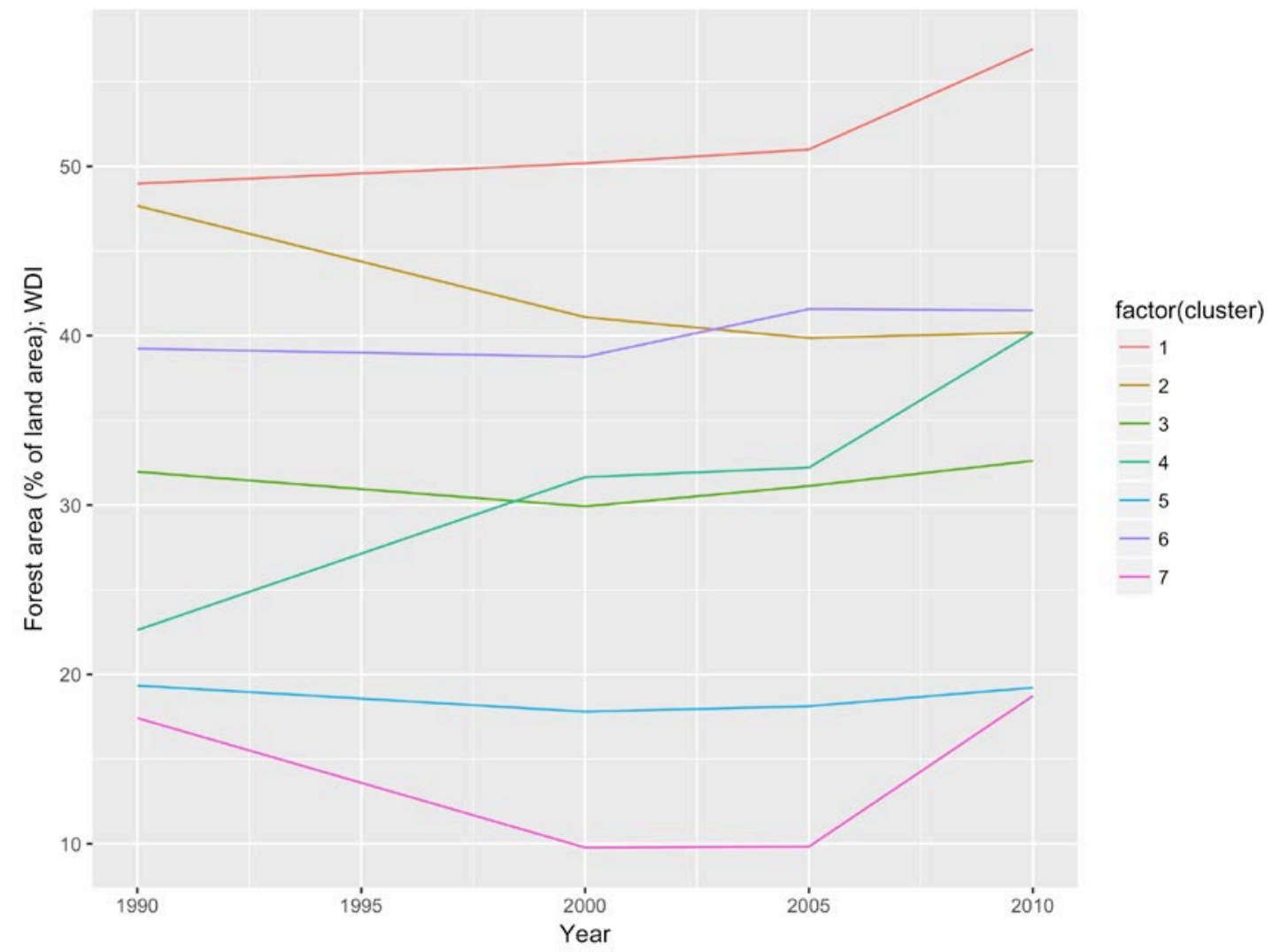

Figures 5 e. Forest area development of the clusters: The reserves per capita are the average of all countries in a cluster in a corresponding year. Note that the countries in a specific cluster vary over time.

As we can see from Figure 5a cluster 5 with a natural gas share of over $43 \%$ in the energy mix had by far the highest average per capita proved reserves of natural gas measured in trillion cubic feet in 2010 (US EIA) throughout the examined period. Similarly, Figure 5b shows the coal endowments, measured as recoverable hard coal in million short tons per capita in 2008 (US EIA) per cluster. Cluster 6 stands out clearly as the energy profile with the highest natural coal endowments on the one hand, and with the highest share of coal use in energy consumption with close to $60 \%$ on the other hand. We also note that movements out of these clusters are sluggish with many countries never changing their positions. Cluster 5 however has seen a number of new entrants in the past twenty years, supported by either discovery of new gas resources or better pipeline access. Figure 5 c presents the recoverable lignite in million short tons per capita (US EIA), with clusters 2 and 4 displaying the highest reserves.

Figures $5 \mathrm{~d}$ and e show average renewable internal freshwater resources per capita in cubic meters, and forest areas as \% of land area (WDI). While large shares of lowgrade biomass use characterize many low-income countries' energy consumption, biomass use at higher income levels usually involves higher-efficiency combustion. Clusters 1-3 display a relatively high use of biomass compared to the other profiles. Accordingly, the highest forest areas per percent of land area are observed also in clusters 1 and 2 . Similarly, clusters $1-3$ show both the highest renewable freshwater resources per capita available and the highest utilization of those resources in the form of hydro energy. Testing the energy profiles identified by our model based clustering 
algorithm with respect to the presence of endowments supports the claim that countries with high own resource endowments use predominantly the locally available energy form.

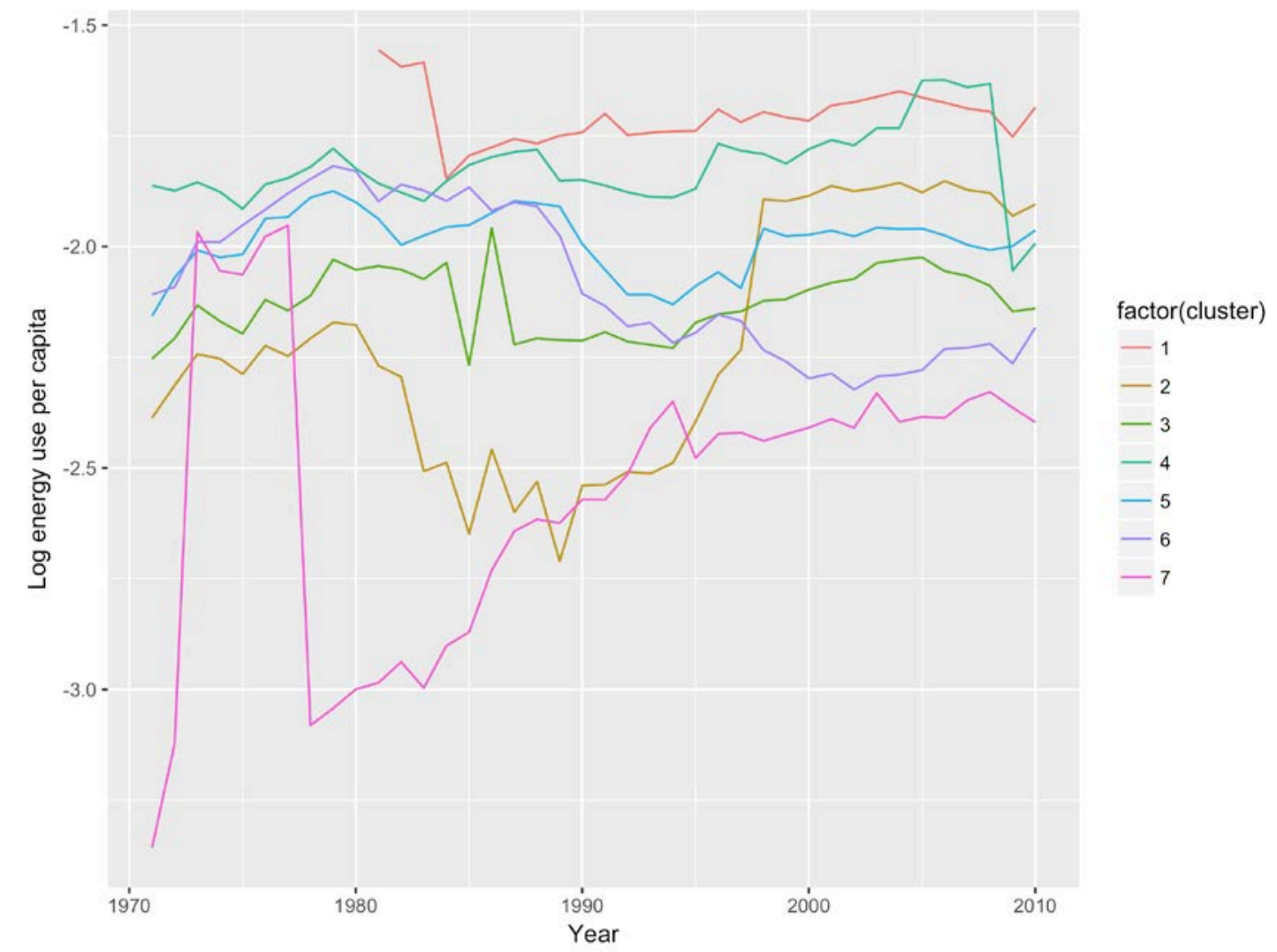

Figure 6. Energy use per capita development of the clusters: The log energy use per capita is the population weighted average of all countries in a cluster in a corresponding year. Note that the countries in a specific cluster vary over time.

Figure 6 presents the weighted average energy use per capita patterns of the different clusters. We can clearly observe that higher-fuel-mix profiles tend to consume the highest per capita primary energy in 2010. This indicates that along the income spectrum countries tend to use more energy per capita on the one hand, however also exhibit higher quality energy mixes on the other hand. Thus the impact of these forces on the carbon intensity of the economy is twofold. Firstly, higher energy use would increase, but a cleaner energy mix would decrease carbon intensity. Observing the development of per capita energy use in the clusters however reveals another story, with strongly decreasing energy use per capita compared to the 1980s for clusters 5 and 6 for example. The energy use per capita of former East Bloc countries drastically reduced after the 1990s, and thus these countries might significantly influence the energy use development of these clusters. At the same time, the energy intensity development of the clusters appears to be reducing and converging over time, as shown in Figure 7. This supports the findings of Csereklyei et al. (2016) that energy intensity is decreasing and converging over time and income. While all clusters have experienced decreasing energy intensity of their economies, the change was most pronounced in case of clusters 4, 5 and 6, which include a number of former transition (Eastern European) countries and showed the highest starting energy-intensity levels. 


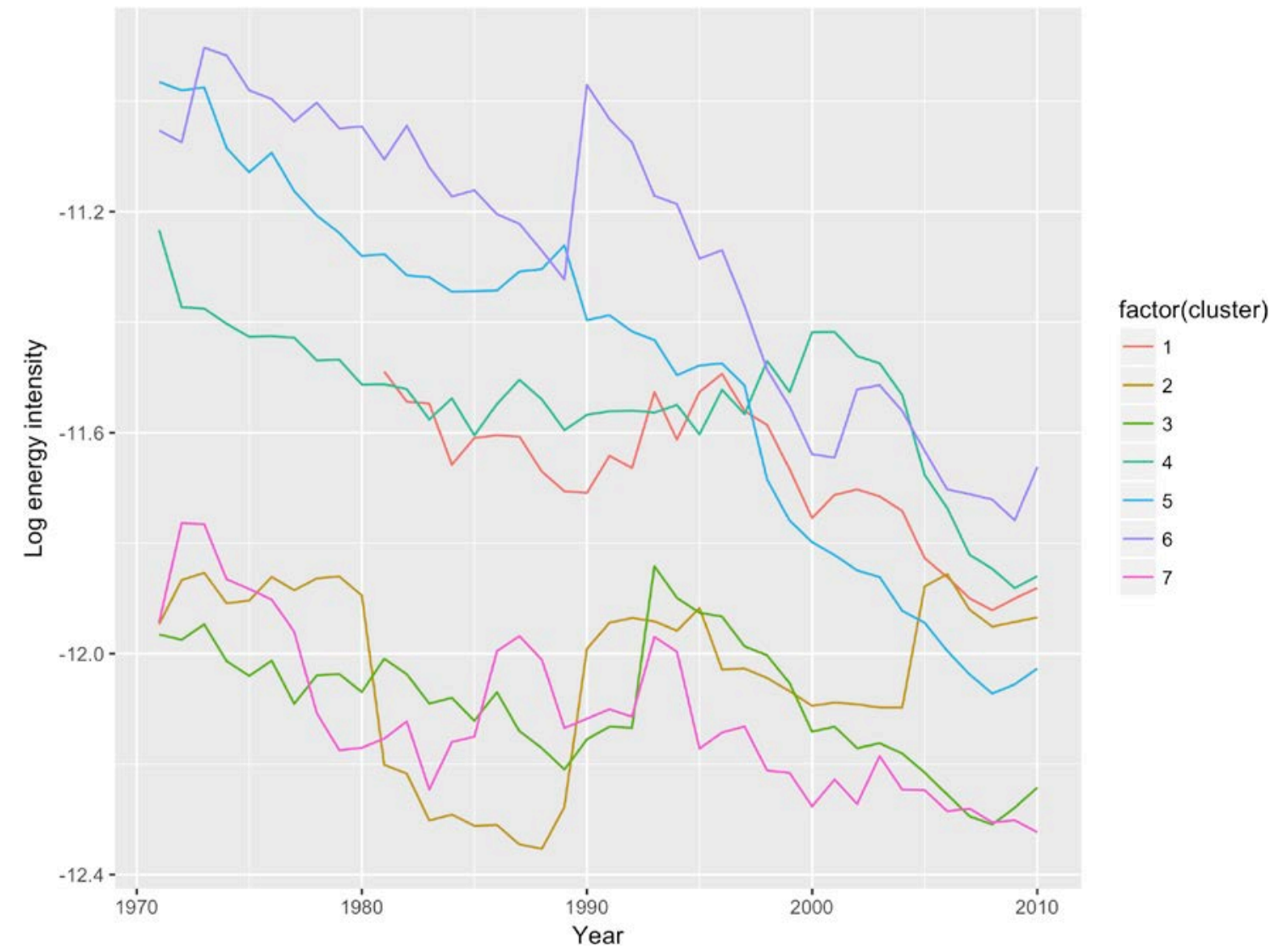

Figure 7. Energy intensity development of the clusters: The log energy intensity is the average of all countries in a cluster in a corresponding year. Note that the countries in a specific cluster vary over time.

The security of energy supply is of crucial importance for the EU, which imports about 53\% of its total energy consumption (European Commission, 2014b). This figure has been continuously growing in the past years, and is expected to further increase in the future. The EU currently imports approximately $90 \%$ of its crude oil use, $66 \%$ of natural gas use, and $42 \%$ of solid fuel use. Especially in case of natural gas imports, the Union is dependent on a single external supplier (European Commission, 2014b).. Figure 8 shows the average import dependency (defined by the World Bank as net energy imports in percent of the total energy use ${ }^{18}$ ) development for each of the energy-profiles over time.

\footnotetext{
18 "Net energy imports are estimated as energy use less production, both measured in oil equivalents. A negative value indicates that the country is a net exporter. Energy use refers to use of primary energy before transformation to other end-use fuels, which is equal to indigenous production plus imports and stock changes, minus exports and fuels supplied to ships and aircraft engaged in international transport.” (World Bank, 2015)
} 


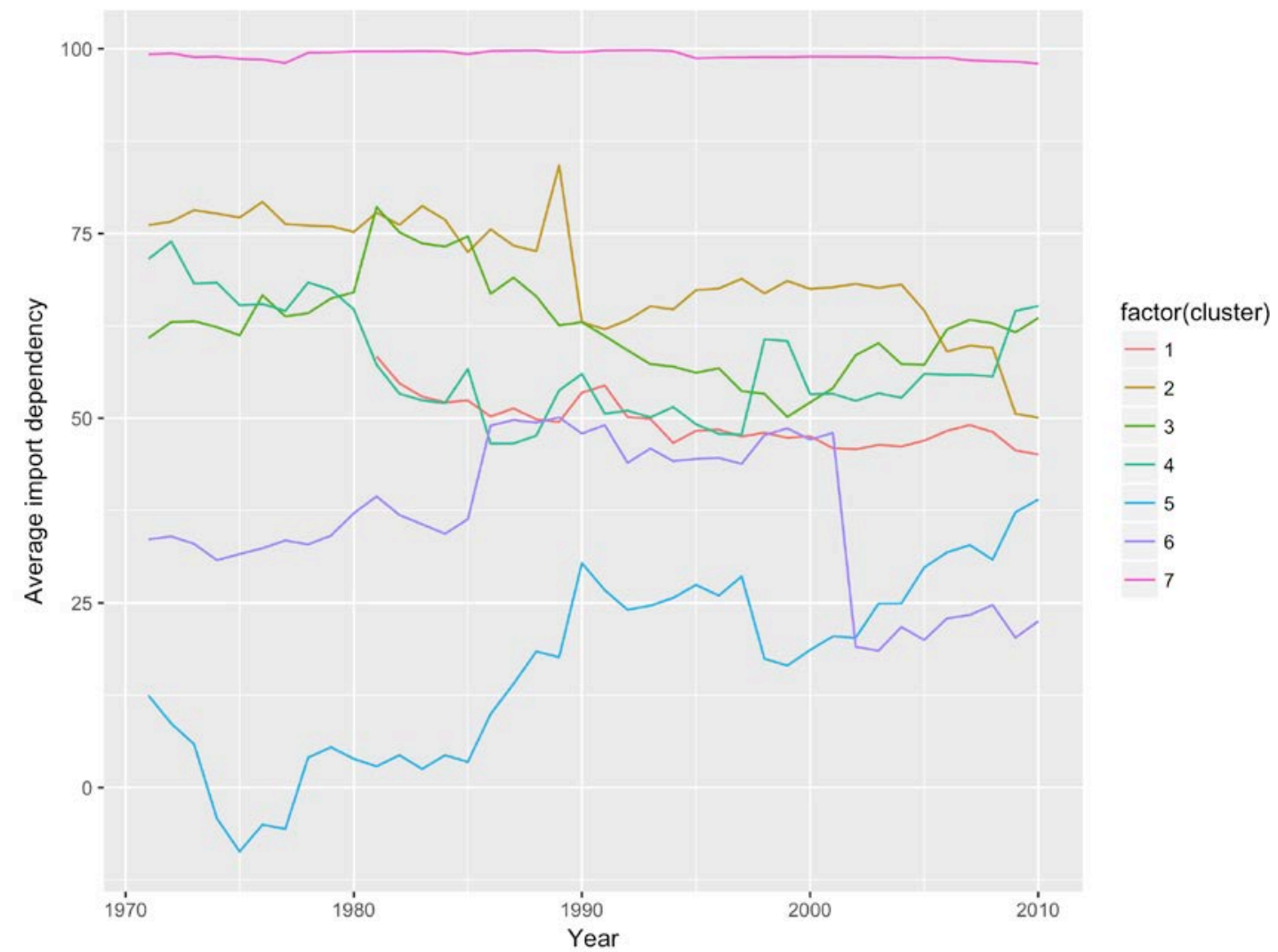

Figure 8. Energy import dependency of the clusters: Average of the World Bank's import dependency measure in the corresponding clusters. Note that the countries in a specific cluster vary over time.

As expected, due to the high oil imports, cluster 7 shows the highest import dependency, followed by clusters 3 and 2 . Both clusters 3 and 2 include close to or above $50 \%$ dependency on oil, with relatively lower coal and gas share in the primary energy mix, resulting in high import dependency. Import dependency is the lowest in clusters 6 and 5, with a relatively high share of indigenous coal and natural gas consumption compared to oil use. While oil consumption may be a major factor contributing to high import dependency, oil supplies are diverse, and may be readily transported by tankers, in case of pipeline problems. Only 20\% of the EU's oil is flowing through pipelines (Bjørnmose et al. 2009) ${ }^{19}$. At the same time natural gas dependency towards a single supplier means high national and energy security risk in case of supply disruptions for any reasons. Firstly, gas markets have a local nature with differing price levels, and liquid natural gas (LNG) transports to harbors can be rather expensive. Bjørnmose et al. (2009) note that a weak structural point of the EU pipeline system is the limited connection between Western and Eastern Europe.

Furthermore the gas infrastructure is not subject to the general competition rules of the EU, but is regulated by Third Party Access. In accordance with this, the proposed energy security strategy of the European Union includes among others the exploitation of indigenous resources including renewable energy, the diversification of suppliers and supply routes, and the effective reduction of energy intensity

${ }^{19}$ More precisely through the Druzhba pipeline running from Russia through the Baltic States to Germany and Poland, with another branch reaching Slovakia and Hungary, and through the Norpipe running from Norway to the United Kingdom. 
(European Commission, 2014a). ${ }^{20}$

\subsection{Country-paths}

Figure 9 depicts the individual country paths between 1971 and 2010. In summarizing the general patterns, out of 28 countries, only six transitioned to clusters with higher average fossil fuel share for various reasons, namely Belgium, Greece, Italy, Lithuania, Portugal and the United Kingdom. From these countries, Belgium is characterized by energy intensive chemical and shipping industries (Eurostat, 2009), and high fossil fuel imports after the closing of its coal mines. Belgium is currently increasingly relying on renewables besides its nuclear power plants (the last of which is planned to be shut down in 2025). The Greek energy system is special, as the country is made up of several islands lacking interconnections between them and the mainland (Eurostat, 2009). Greek indigenous resources are rich in lignite, causing a lock-in in lignite power generation. Due to the high oil and lesser gas imports, the country has a relatively high import dependency. Italy moved from cluster 2 to 3 in 1987, a year before the country's nuclear power plants were turned off after a moratorium on nuclear power. Similarly to Italy, the Lithuanian transition is also owed to the shutting down of Lithuania's nuclear power plants upon EU entry.

Portugal has almost no indigenous resources and is entirely dependent on the imports of fossil fuels. According to Eurostat (2009) its energy growth has been higher than the corresponding economic growth in the last decade, therefore the country's energy intensity increased, against the general trend. The United Kingdom on the other hand is rich both in coal, North Sea oil and gas (the production of which peaked around 2000 (Eurostat, 2009)), and is one of the oldest civilian nuclear state. Due to the large amount of domestic gas available, the country transitioned from coal towards gas powered electricity generation during the past years. This transition is clearly depicted by the change of clusters from cluster 4 to 5 .

Ten countries never changed clusters during the observation period, namely Austria, Croatia, Cyprus, Estonia, Latvia, the Netherlands, Poland, Romania, the Slovak Republic and Slovenia. Further two countries ended in the same cluster they started in, with minor fluctuations, including Spain and Malta. These countries can be separated into three distinctive groups, with different potential drivers or combination of drivers for lock-in. The first group is characterized by geographical lock-in, the second-group by infrastructural and grid system inertia, and the third group is driven by path dependencies due to abundant domestic energy resources.

The islands of Cyprus and Malta belong to the first group, almost exclusively dependent on imported petroleum consumption. The second group includes countries with low or no indigenous fossil or hydro resources, however with a distinct infrastructural, grid and pipeline lock in, such as Slovenia and Slovakia, both of which utilize nuclear energy and are transit countries for gas. Abundant indigenous resources are at work on the other hand in the third group, including Estonia with significant oil shale reserves, accounting for $90 \%$ of its power production and $70 \%$ of its primary energy use (US EIA, 2015). Poland possesses the largest coal reserves in

\footnotetext{
20 The Commission estimates that avoided imported fuel costs due to increasing use of renewable energy amounted to at least some EUR 30 billion a year.
} 
Europe and relied on coal and lignite to cover almost 55\% of its primary energy consumption in 2012 (US EIA, 2015). While its fossil fuel dependence is among the highest, the country has a low energy import dependency. ${ }^{21}$ Another country with significant fossil reserves is Romania. The Netherlands relies primarily on its natural gas, well-connected international grids and is the second largest gas producer in Europe after Norway (US EIA, 2015). Nevertheless it imports a large share of its petroleum products, making up about $50 \%$ of its primary consumption (US EIA, 2015). Countries relying heavily on non-fossil fuel reserves include Austria and Latvia, both of which take advantage of their hydropower capacities. Latvia in addition has significant biomass resources in the form of wood (Eurostat, 2009).

The last group of ten countries, including Bulgaria, the Czech Republic, Denmark, Finland, France, Germany, Hungary, Ireland, Luxembourg, and Sweden tended to move towards higher quality energy mixes. One common factor is that many of these countries built up a large nuclear energy production share in the primary energy mix by 2010 that enabled them to substitute away from fossil fuels. Apparently in the absence or in the limited presence of large hydro-power capacities and endowments, the only alternative energy form enabling a significant reduction of fossil fuel dependence was nuclear energy in the past.

Of these countries, Bulgaria, the Czech Republic, Finland, France, Germany, Hungary and Sweden possess nuclear power plants. Most prominently the French energy strategy is dominated by nuclear energy, providing about $40 \%$ of the total primary energy consumption. The past nuclear expansion in France was based on a clear political decision to reduce dependence on imported fuels. Another important French energy policy concerned energy efficiency, which resulted in France being one of the most energy efficient countries in Europe (Eurostat, 2009). Currently Finland is the only country besides France engaging in the building of a new ERP reactor, simultaneously to the planned construction of a Russian designed reactor. Sweden takes also advantage its large biomass reserves, its nuclear and hydro energy, and strong energy efficiency programs. Germany is currently characterized by the increasing share of renewables, but also by increased coal usage after the shut-down of its nuclear power plants in 2011. However, since our dataset runs only until 2010, we do not yet see this transition. Quite contrary to the German nuclear policy, Hungary is currently seeking to extend its nuclear power, which is already supplying the majority of its power generation. Non-nuclear states that improved their positions include Denmark, Ireland and Luxembourg. Denmark possesses large quantities of North Sea oil and gas, yet promoted renewable energy and energy efficiency measures, developing one of the most successful wind-electricity programs in the world.

Changes in energy paths - if these occur - take a long time. We see that the average number of cluster leaps is 0.85 . Countries spend decades in a certain cluster before moving different ones, either as a result of energy policies, economic development or due to the availability of a new dominant energy form.

21 Accordingly, Poland was the only EU member state, not in favor of a GHG reduction target for 2030 during a public consultation on the 2030 framework for climate and energy policies (European Commission, 2013). 
Cluster occupation 1971

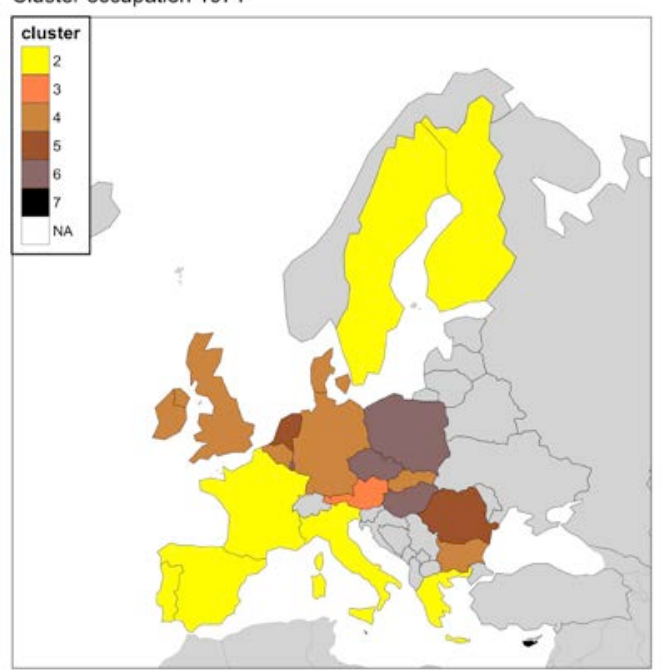

Cluster occupation 1991
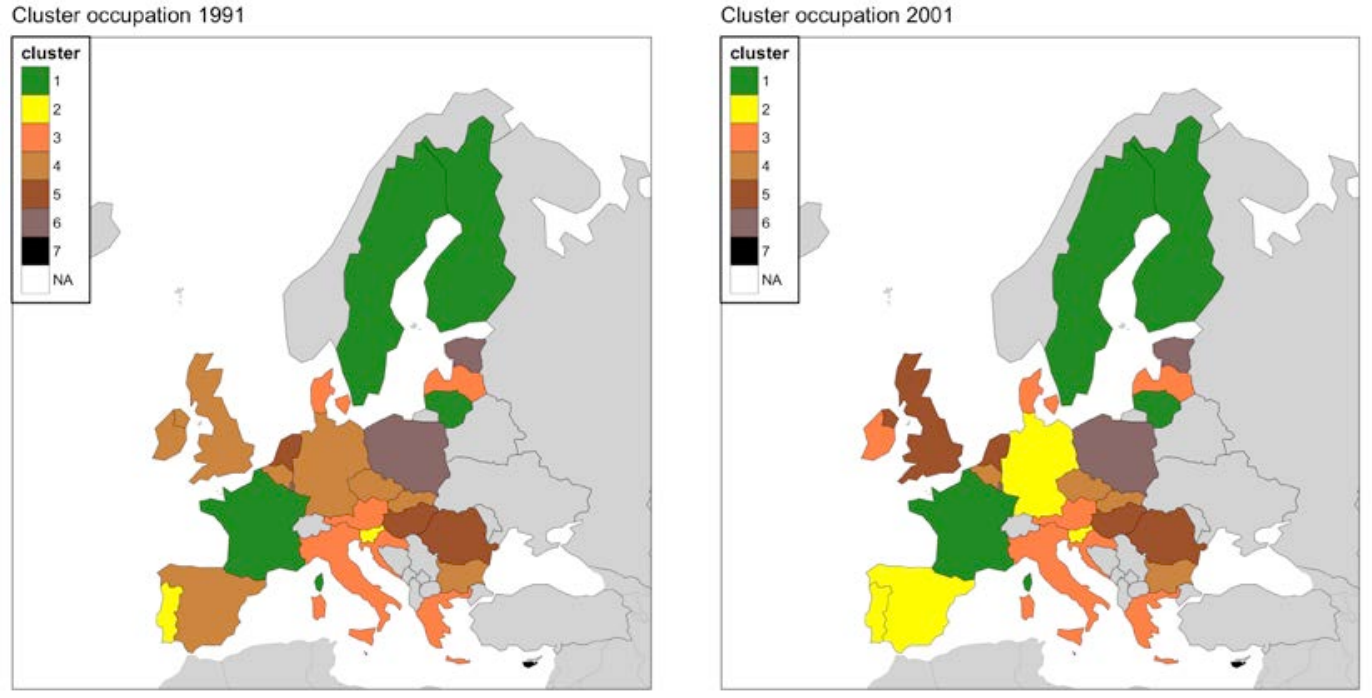

Cluster occupation 1981

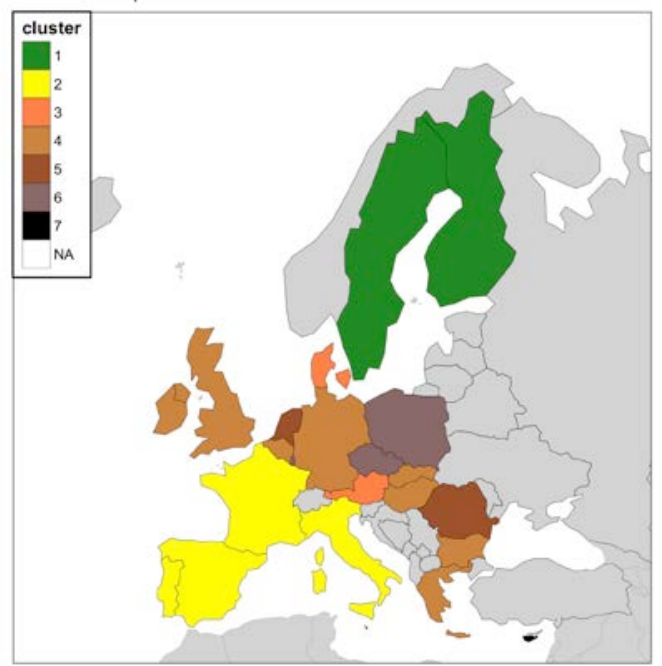

Cluster occupation 2010

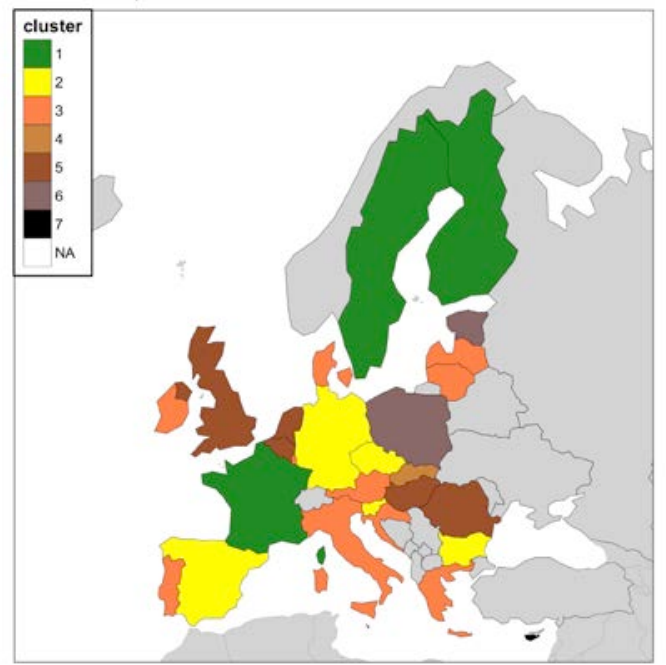




\section{Conclusions and Policy Implications}

Energy transitions of the future carry enormous implications for both the security of energy supply and the environment, as well as for the quest to combat global warming. Using model-based clustering, not previously applied to the topic, we examined the "energy paths" i.e. the intertemporal development of the energy mixes of the member states of the European Union over 1971-2010. We identified seven distinct energy profiles, which we ranked from highest to lowest combined fossil fuel content.

We find that countries tended to embark on a path towards higher quality energy mixes, and tended to reduce their dependence on fossil fuels over the examined period, unless path dependencies related to high indigenous resources, existing infrastructure, or geographical constraints existed. Significant reduction in fossil-fuel dependence over time was only achieved by states that deployed a combination of nuclear energy, hydropower, and renewable energy. It is true that renewable energy began to gain importance in electricity generation over the past decade, however, since electricity accounts for only a fraction of primary energy use, the total share of renewables in the primary energy mix is still low. A future area of research could be therefore to apply our methods to the electricity generation mix.

The energy-GDP relationship displayed by our energy profiles show some evidence on the existence of a national-level energy ladder, meaning that higher energy-quality profiles tend to be associated with higher income and energy usage per capita. Also, high-income countries were likelier to embark on a transition away from high-fossil fuel usage, even in the presence of considerable own resources. Path dependencies caused by own resources are clearly identifiable in the composition and "inhabitancy" of the profiles. We find that clusters with the highest coal and natural gas usage respectively included countries with the largest coal and natural gas endowments per capita. Similarly, high share of forests and freshwater per capita endowments were associated with a relatively high usage of biomass and hydro energy across all observations.

Our results also identify energy intensity convergence across time and the income spectrum. While the average income of all clusters is increasing over time, energy intensity is decreasing. This drop is most pronounced in clusters that exhibited the highest energy intensity at the beginning of the period. Our results are thus in line with the findings of previous authors and suggest that continued economic growth will result in increasing quality of the primary energy mix. While endowments in renewable energy increase the above process, fossil resources have the ability to considerably delay it.

\section{References}

Aghabozorgi, S., A.S. Shirkhorshidi, T.H. Wah (2015). Time-series clustering - A decade review, Information Systems 53: 16-38.

Ahlquist J.S., C. Breunig (2012). Model-based Clustering and Typologies in the Social Sciences, Political Analysis 20: 92-112. 
Araujo, L., D. Harrison (2010). Path Dependence, Agency and Technological Evolution, Technology Analysis \& Strategic Management, 14(1): 5-19.

Araújo, K. (2014). The emerging field of energy transitions: Progress, challenges, and opportunities, Energy Research \& Social Science 1: 112-121.

Burke, P.J., G. Dundas (2015). Female Labor Force Participation and Household Dependence on Biomass Energy: Evidence from National Longitudinal Data, World Development 67: 424-437.

Burke, P.J. (2010). Income, resources, and electricity mix, Energy Economics 32: 616-626.

Burke, P. J. (2013). The National-Level Energy Ladder and Its Carbon Implications, Environment and Development Economics 18(4): 484-503.

Bjørnmose, J., F. Roca, T. Turgot, D. Smederup Hansen (2009). An Assessment of the Gas and Oil Pipelines in Europe, IP/A/ITRE/NT/2009-13, PE 416.239, European Parliament.

Bousquet, A., M. Ivaldi (1998). An individual choice model of energy mix, Resource and Energy Economics, 20: 263-286.

Chabrol, M. (2016). Re-examining historical energy transitions and urban systems in Europe, Energy Research \& Social Science 13: 194-201.

Cherp, A., J. Jewell (2014). The concept of energy security: Beyond the four As, Energy Policy 75: 415-421.

Csereklyei, Z., MdM Rubio-Varas, D.I. Stern (2016). Energy and economic growth: The stylized facts, Energy Journal, 37(2):223-255.

Csereklyei, Z., D.I. Stern (2015). Global energy use: Decoupling or convergence?, Energy Economics, 51:633-641.

Dempster A.P., N.M. Laird, D.B. Rubin (1977). Maximum Likelihood from Incomplete Data via the EM Algorithm, Journal of the Royal Statistical Society, Series B (Methodological)

39(1):1-38.

Duan, P., K. Xie, T. Guo, X. Huang (2011). Short-Term Load Forecasting for Electric Power Systems Using the PSO-SVR and FCM Clustering Techniques, Energies 4:173-184.

Duić, N, Z. Guzović, V. Kafarov, J. J. Klemeš, B. v. Mathiessen, J. Yan (2013). Sustainable development of energy, water and environment systems, Applied Energy, 101: 3-5.

Dziak, J.J., D.L. Coffman, S.T. Lanza, R. Li (2012). Sensitivity and specificity of information criteria, The Pennsylvania State University, Technical Report Series 12119. 
European Commission (2013). Results of the public consultation on the 2030 framework for climate and energy policies.

European Commission (2014a). A policy framework for climate and energy in the period from 2020 to 2030 [COM(2014) 15], EUR-Lex - 52014DC0015 - EN.

European Commission (2014b). Communication from the Commission to the European Parliament and the Council: European Energy Security Strategy, SWD(2014) 330.

Eurostat (2015). Renewable Energy Statistics, http://ec.europa.eu/eurostat/statisticsexplained/index.php/Renewable_energy_statistics.

Eurostat (2009). Panorama of Energy, ISSN 1831-3256.

Foidart, F., J. Oliver-Sola, C.M. Gasol, X. Gabarrell, J. Rieradevall (2010). How important are current energy mix choices on future sustainability? Case study: Belgium and Spain—projections towards 2020-2030, Energy Policy 38: 5028-5037.

Fouquet, R., P.J.G. Pearson (2012). Past and prospective energy transitions: Insights from history Editorial / Energy Policy 50: 1-7.

Fouquet R. (2012). The demand for environmental quality in driving transitions to low-polluting energy sources. Energy Policy (Special Issue on Past and Prospective Energy Transitions) 50: 130-141.

Fraley, C., A.E. Raftery (2005). Bayesian regularization for normal mixture estimation and model-based clustering. Technical Report No. 486. Department of Statistics, University of Washington.

Fraley, C., A.E. Raftery (2007). Bayesian Regularization for Normal Mixture Estimation and Model-Based Clustering, Journal of Classification 24: 155-181.

Fraley C, A E. Raftery, T. B. Murphy, L. Scrucca (2012). mclust Version 4 for R: Normal Mixture Modeling for Model-Based Clustering, Classification, and Density Estimation Technical Report No. 597, Department of Statistics, University of Washington.

Fraley C., A.E. Raftery (2002). Model-based Clustering, Discriminant Analysis and Density Estimation, Journal of the American Statistical Association 97: 611-631.

R. Gross, W. Blyth, P. Heptonstall (2010). Risks, revenues and investment in electricity generation: Why policy needs to look beyond costs, Energy Economics 32: 796-804.

Gales, B., A. Kander, P. Malanima, and M. Rubio (2007). North versus South: Energy Transition and Energy Intensity in Europe over 200 Years. European Review of Economic History 11: 219-253.

Grübler, A., N. Nakicenovic (1991). Long waves, technology diffusion and substitution. Review 14: 313-342. 
Grübler, A. (2004).Transitions in energy use, Encyclopedia of Energy 6: 163-177.

Grübler. A (2012). Energy transitions research: Insights and cautionary tales, Energy Policy 50: 8-16.

Grübler, A., N. Nakicenovic, and D.G. Victor (1999). Dynamics of energy technologies and global change, Energy Policy 27: 247-280.

Heston, A., R. Summers, and B. Aten (2012). Penn World Table Version 7.1. Center for International Comparisons of Production, Income and Prices at the University of Pennsylvania.

Hirth, L. (2015). Market value of solar power: Is photovoltaics cost-competitive?, IET Renewable Power Generation 9(1): 37-45.

Hosier, R.H. (2004). Energy ladder in developing countries, Encyclopedia of Energy 2: 423-435.

Hosier, R.H. and J. Dowd (1987). Household fuel choice in Zimbabwe: an empirical test of the energy ladder hypothesis, Resources and Energy 9: 347-361.

Heltberg, R. (2004). Fuel switching: evidence from eight developing countries, Energy Economics 26: 869-887.

Hsu, D. (2015). Comparison of integrated clustering methods for accurate and stable prediction of building energy consumption data, Applied Energy, 160: 153-163.

Iglesias, F., W. Kastner (2013). Analysis of Similarity Measures in Times Series Clustering for the Discovery of Building Energy Patterns, Energies 6: 579-597.

IEA-International Energy Agency (2013). Energy Balances of Non-OECD Countries 2013, OECD/IEA: Paris.

IEA-International Energy Agency (2014a). Energy Supply Security, Emergency Response of IEA Countries 2014, OECD/IEA: Paris.

IEA-International Energy Agency (2014b). Energy Policies of IEA Countries 2014, European Union, OECD/IEA: Paris.

Jewell, J. (2011). The IEA Model of Short-Term Energy Security (MOSES): Primary Energy Sources and Secondary Fuels, IEA Energy Papers, OECD.

Judson, R.A., R. Schmalensee, and T.M. Stoker (1999). Economic development and the structure of the demand for commercial energy, Energy Journal 20: 29-57.

van der Kroon, B., R. Brouwer, P.J.H. van Beukering (2013).The energy ladder: Theoretical myth or empirical truth? Results from a meta-analysis, Renewable and Sustainable Energy Reviews 20: 504-513.

Lee, R. P., S. Gloaguen (2015). Path-dependence, lock-in, and student perceptions of nuclear energy in France: Implications from a pilot study, Energy Research \& Social Science 8: 86-99. 
Li, X., C.P. Bowers, T. Schnier (2010). Classification of Energy Consumption in Buildings With Outlier Detection IEEE Transactions on Industrial Electronics 57(11):3639-3644.

Liao, T.W. (2005). Clustering of time series data-a survey, Pattern Recognition 38 : 1857-1874.

Liu, D., J. Wang, H. Wang (2015). Short-term wind speed forecasting based on spectral clustering and optimised echo state networks, Renewable Energy 78 :599608.

Marchetti, C. (1977). Primary energy substitution models: on the interaction between energy and society, Technological Forecasting and Social Change 10: 345-356.

Marrero, G.A. (2010). Greenhouse gases emissions, growth and the energy mix in Europe, Energy Economics 32:1356-1363.

Pierson, P. (2000). Increasing Returns, Path Dependence, and the Study of Politics, The American Political Science Review, 94(2): 251-267.

Raftery, A. E., N. Dean (2006). Variable selection for model-based clustering. Journal of the American Statistical Association 101(473): 168-78.

Rubio, M.d.M., M. Folchi (2012). Will small energy consumers be faster in transition? Evidence from the early shift from coal to oil in Latin America. Energy Policy 50: 50-61.

Schaffer, L.M., T. Bernauer (2014). Explaining government choices for promoting renewable energy, Energy Policy 68: 15-27.

Sovacool, B.K. (2016). How long will it take? Conceptualizing the temporal dynamics of energy transitions, Energy Research \& Social Science 13: 202-215.

Stern, D. I. (2010). Energy Quality, Ecological Economics 69(7): 1471-1478.

Stern, D. I. (2012). Modeling International Trends in Energy Efficiency, Energy Economics 34: 2200-2208.

Stramboa, C., M. Nilssona, A. Månssonc (2015). Coherent or inconsistent? Assessing energy security and climate policy interaction within the European Union, Energy Research \& Social Science 8: 1-12.

Tahvonen, O., S. Salo (2001). Economic growth and transitions between renewable and nonrenewable energy resources, European Economic Review 45: 1379-1398.

US EIA (2015). International Country Profiles: http://www.eia.gov/beta/international/ Yang, T. (2015). Dynamic assessment of environmental damage based on the optimal clustering criterion - Taking oil spill damage to marine ecological environment as an example, Ecological Indicators 51:53-58.

Yergin, D. (2006). Ensuring Energy Security, Foreign Affairs 85(2): 69-82. 
World Bank (2015). World Development Indicators, http://data.worldbank.org/datacatalog/world-development-indicators. 